\title{
Application of Pulsed Thermography and Post-processing Techniques for CFRP Industrial Components
}

\author{
F. W. Panella ${ }^{1}$ A. Pirinu ${ }^{1}$ (1) \\ Received: 8 April 2020 / Accepted: 15 May 2021 / Published online: 4 June 2021 \\ (c) The Author(s) 2021
}

\begin{abstract}
Several studies demonstrate the effectiveness of pulsed thermography for detection and visualization of sub-superficial flaws in composites. Continuous improvement of thermal data manipulation makes active thermography an attractive and powerful inspection method for industrial process control and maintenance aims. Therefore, temperature image-processing is the major ongoing challenge in the thermographic research field. However, the particular interest for thermographic inspections is to be more addressed to its simple and relatively fast industrial application; an appropriate image processing tool should be implemented and verified on industrial components, containing manufacturing and in-service defects. In the proposed research, well-established and previously proposed methods were analysed and compared for different defect typology inside three CFRP components. The main goal is not solely focused on establishing the suitable data processing approach, providing detection limits of processed data in terms of damage type, size and distribution. The aim of proposed work is to present detailed examples of thermal imaging methods applied on similar critical defects, evaluating different results among methods in terms of defects mapping capabilities and Tanimoto evaluation criterion, coupled also with the signal-to-noise ratio as assessment of defect detectability.
\end{abstract}

Keywords Artificial defects $\cdot$ Carbon fiber reinforced polymer $\cdot$ Delamination $\cdot$ Image-processing $\cdot$ Non-destructive controls $\cdot$ Porosity $\cdot$ Thermography

$\begin{array}{ll}\text { Abbreviations } \\ \text { CFRP } & \text { Carbon fiber reinforced plastic } \\ \text { DAC } & \text { Differential absolute contrast } \\ \text { DIC } & \text { Digital image correlation } \\ \text { EOF } & \text { Empirical orthogonal function } \\ \text { FPA } & \text { Focal-plane array } \\ \text { GUI } & \text { Graphical user interface } \\ \text { IDAC } & \text { Interpolated differential absolute contrast } \\ \text { IRT } & \text { Infrared thermography } \\ \text { LBC } & \text { Local boundary contrast } \\ \text { NAN } & \text { Not a number } \\ \text { NDT } & \text { Non-destructive testing } \\ \text { NETD } & \text { Noise equivalent temperature differences } \\ \text { PCT } & \text { Principal component thermography } \\ \text { PT } & \text { Pulsed thermography } \\ \text { SHM } & \text { Structural health monitoring } \\ \text { SNR } & \text { Signal to noise }\end{array}$

A. Pirinu

alessandra.pirinu@unisalento.it

1 Department of Engineering for Innovation, University of Salento, 73100 Lecce, Italy
SVD Singular value decomposition

TSR Thermal signal reconstruction

\section{Introduction}

In recent years, ecological efficiency of aerospace manufacturing and sustainability economic aspects provide a significant incentive for increasing implementation of Carbon Fiber Reinforced Polymers (CFRP) in industrial structures $[1,2]$. Specific physical and mechanical property makes these materials very attractive to the transportation industry, i.e. lightweight, elevated stiffness and a good resistance against corrosion and fatigue, reducing both the fuel consumption and the emissions of greenhouse gases [3, 4]. Therefore, continuous improvement of Non-destructive testing (NDT) and the advanced solutions of Structural health monitoring (SHM) represent the major challenge for composites, in order to improve structural reliability and integrity [5-8]. Several research studies demonstrated that different defects and damage phenomena may arise either during production or in-service loading, leading to possible 
failure of these thin and layered structures [5, 6, 9]. A suitable ND control approach is the critical aspect for component inspection to certain integrity assessment [10]. Pulsed thermography (PT) represents a no-contact and full-field ND technique, widely used for the industrial controls of large composite surfaces due to wide detection area, fast and relatively simple detection $[11,12]$. In recent years, the enhancement of visual image modality, combined with fast and robust temperature processing strategy has significantly grown for a multi-functionality of Infrared thermography for specific industrial applications, characterized by difficult to inspection components or as requirement of faster inspection [13-16]. Therefore, the image-processing methods and their continuous improvement make the thermographic inspection even more suitable alternative to popular ND controls, as ultrasonic testing, for different production environments $[12,16]$. In literature, different algorithms were proposed to enhance defect detection in terms of dimension, depth and shape $[15,17,18]$.

In this work, the research focus lies on contrast-based methods (normalized contrast and Differential Absolute Contrast) [19-21], statistical methods with skewness, kurtosis and Thermal Signal Reconstruction (TSR) [22, 23], method based on transforms (Principal Component Thermography (PCT)) [24] and two proposed post-processing methods that provide elaborated maps in order to increase defect recognition with its surrounding area and to reduce negative effects related to non-uniform heat distribution [25]. Therefore, a comparative analysis of different methods is preferred to include example results on real parts. In the present paper, a comparative analysis for detectability enhancement is performed on three different cases of study with CFRP elements containing artificial and real production defects and delaminations created also by static load
[26, 27]. Both standard processing techniques (statistical, contrast and methods based on transforms) and the present author suggested method are evaluated in terms of defect mapping characteristics, using Tanimoto criterion [28] and signal to noise ratio (SNR) [29]. Figure 1 shows a simplified block diagram that briefly shows the research paper path for NDT inspections, presenting the inspected material properties (Sect. "Composite Elements"), the basic experimental procedures (Sect. "Thermographic Experimental Setup"), the fundamental aspects of implemented thermal data postprocessing methods (Sect. "Post-processing Techniques"), analysis of results for all combined parts and analyses (Sect. "Results and Discussion") and the final conclusions (Sect. "Conclusions").

\section{Materials and Methods}

\subsection{Composite Elements}

For IR inspections, all examined surfaces are treated with black matte paint to reduce reflections and non-uniform thermal heating on inspected surface. Reference composite element is a CFRP aeronautical specimen (Dim. $120.7 \times 120.7 \times 7.7 \mathrm{~mm}^{3}$ ), assembled with two plates of aeronautical production but different thickness, employed in previous works [26]. Internal defects arrangement and features are reported respectively in Fig. 2a and in Table 1; thirteen polymeric inserts of $5 \div 25 \mathrm{~mm}$ diameter and $0.4 \mathrm{~mm}$ thick are inserted at $2.8 \mathrm{~mm}$ depth, as seen in previous works [26].

The second case of study is represented by an aeronautical CFRP multi-stringer panel of medium size (Dim. $914.4 \times 762 \mathrm{~mm}$ ) with an artificial central discontinuity (Dim. $152.4 \times 6.35 \mathrm{~mm}^{2}$ ) as a large cut, orthogonal to

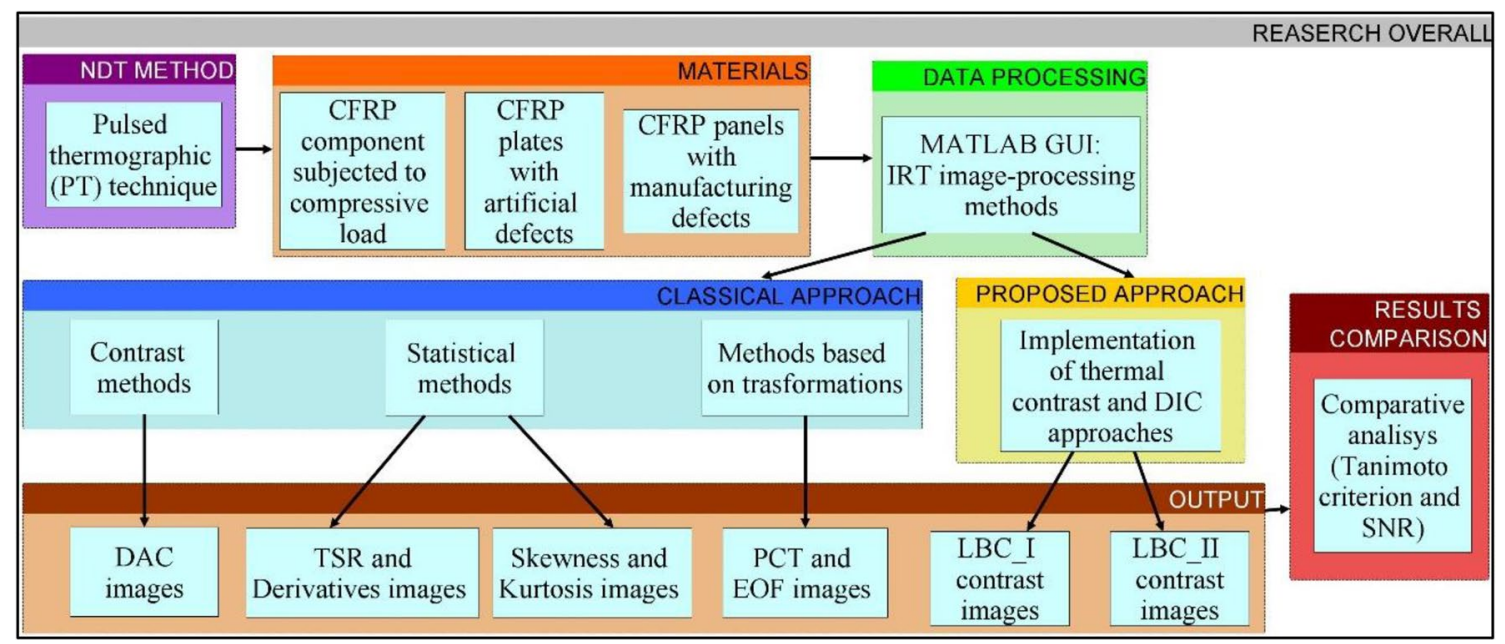

Fig. 1 Research plan overview 


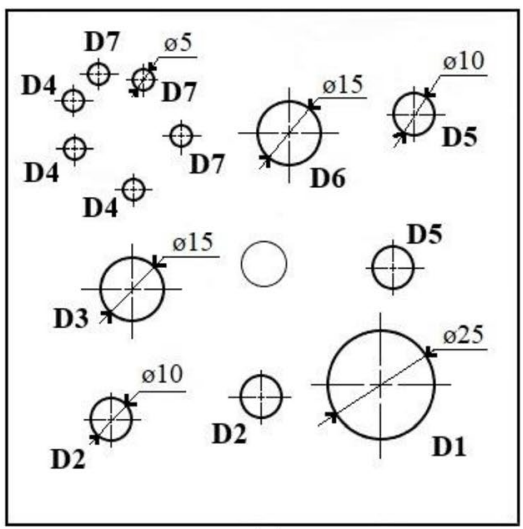

(a)

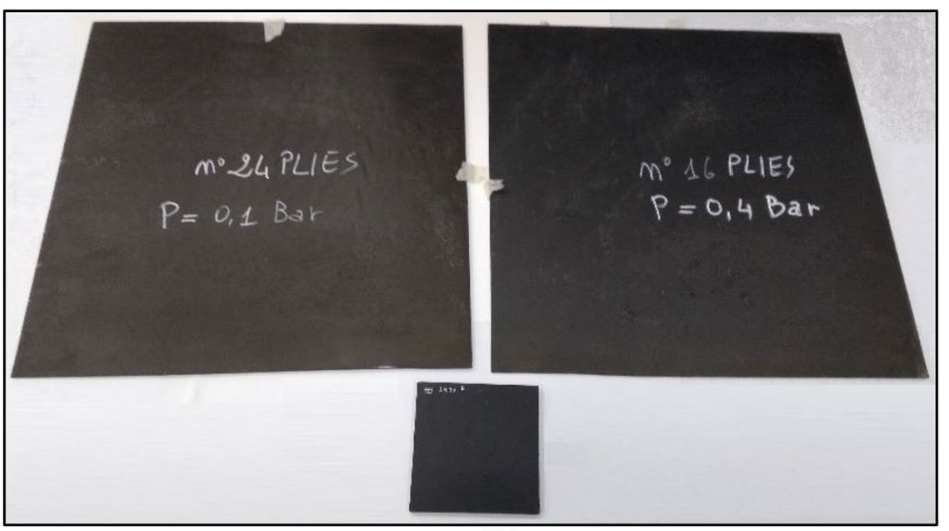

(b)

Fig. 2 a Artificial Defect configuration of reference plate [26]; b reference plate and flat Panels (24 and 16 plies) [26, 27]

Table 1 Defects characteristics of all CFRP analysed components [26, 27]

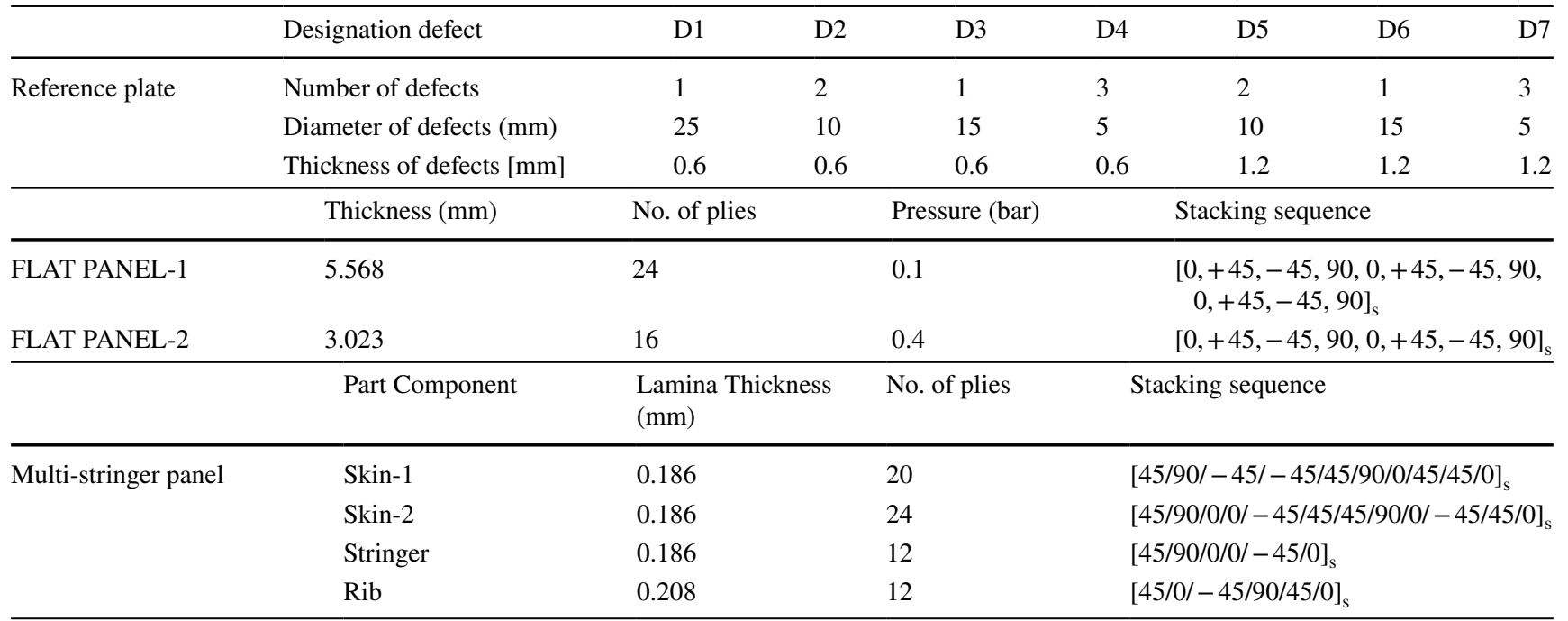

stringer and loading direction. This discontinuity should simulate the effect of a heavy impact and interruption of the central stringer continuity, leading panel collapse in the central zone due to compression, which is expected to produce localized delaminations during static test before final failure. In previous works, this tested CFRP element was previously analysed with ultrasonic inspections, indicating extended delamination damage, accumulated around the artificial discontinuity [26]. Structural geometry and material information are reported respectively in Fig. 3a in Table 1.

Finally, the widespread internal porosity of two CFRP flat plates (Dim. $400 \times 400 \times 3 \div 6 \mathrm{~mm}^{3}$ ) is evaluated in as shown in Fig. 2b; this manufacturing anomaly was introduced through pressure variation during curing cycles of composite elements in a vacuum bag in an autoclave [27]. The stacking sequence, number of plies and cure pressure for each laminated panel are indicated in Table 1.

\subsection{Thermographic Experimental Setup}

After numerous trials, the optimal experimental configuration and thermal acquisition parameters for each CFRP element are described respectively in Fig. $3 \mathrm{~b}$ and in Table 2. Relative heating times are selected for each component on the bases on experience by the authors and according to defect depth [26] and element thicknesses; Many inspections are performed, and the two most interesting ones are presented for both CFRP flat panels on relatives upper and lower sectors. For what concerns the multi-stringer element and reference plate, inspections are performed only in the central zone and only the optimal inspection with frame rate $20 \mathrm{~s}$ are presented in Table.

The main tests results are presented for selected cases of study, performed with pulsed thermographic technique in a thermal controlled laboratory, monitored by 


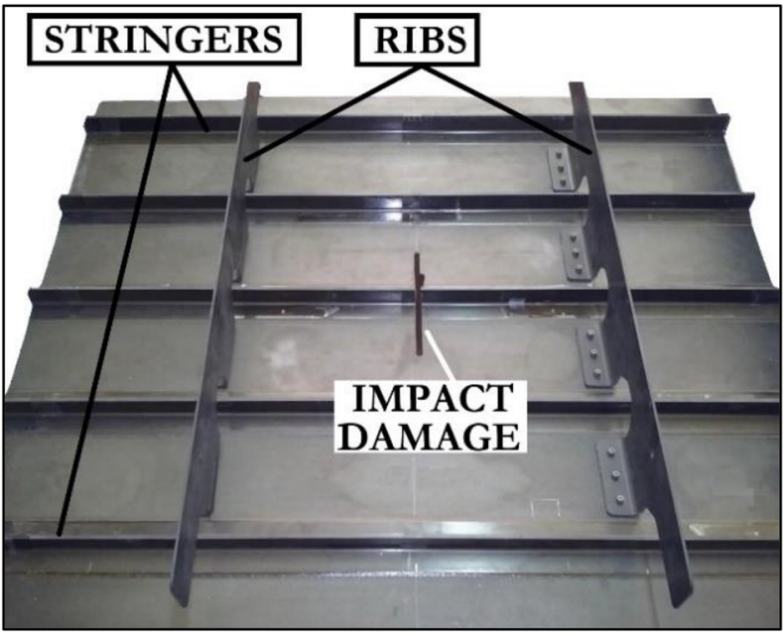

(a)

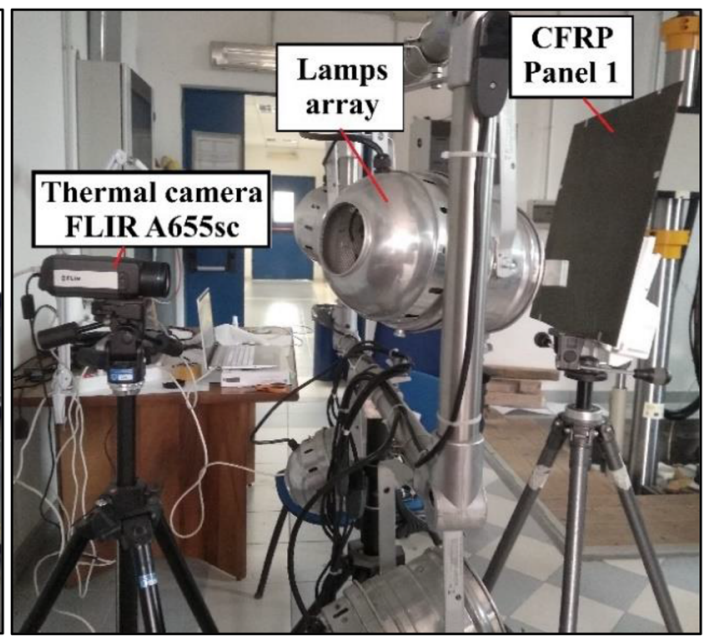

(b)

Fig. 3 a Multi-stringer CFRP panel [26]; b experimental layout for flat Panel-1 with porosity

Table 2 Experimental parameters for IRT investigations

\begin{tabular}{llllll}
\hline CFRP component & Defect depth $(\mathrm{mm})$ & Frame rate $(\mathrm{Hz})$ & $\begin{array}{l}\text { Heating } \\
\text { time }(\mathrm{s})\end{array}$ & $\begin{array}{l}\text { Acquisition } \\
\text { time }(\mathrm{s})\end{array}$ & Total frames \\
\hline Reference plate & 2.8 & 5 & 20 & 120 & 600 \\
Multi-stringer panel & $2-4$ & 5 & 3 & 30 & 150 \\
Panel 1-upper sector & Not available & 6.25 & 3 & 100 & 625 \\
Panel 1-lower sector & Not available & 6.25 & 3 & 100 & 625 \\
Panel 2-upper sector & Not available & 6.25 & 6 & 100 & 625 \\
Panel 2-lower sector & Not available & 6.25 & 6 & 100 & 625 \\
\hline
\end{tabular}

Humidity/Temperature Data Logger. The infrared setup involves thermal excitation source composed of four $1000 \mathrm{~W}$ halogen lamps controlled by a signal generator to set lamp power and signal wave form, as a single square pulse. Temperature image acquisition system employed is a thermal camera, equipped with an uncooled, highly reliable micro-bolometric sensor, which produces thermal images at $640 \times 480$ pixels of high-quality resolution and measurement accuracy and stability. FLIR A655sc makes temperature differences of only $30 \mathrm{mK}$ visible and produces 14-bit data at up to 50 frames per second. Its high-speed windowing feature boosts the frame rate up to $200 \mathrm{~Hz}$, with $640 \times 120$ pixels per window.

A controller dimmer power source is triggered to synchronize simultaneously the thermal pulse to thermal camera recording start. Experimental arrangement and suitable heating times of each inspected elements were studied for CFRP applications in practical experience of previous works [26, 27].

\subsection{Post-processing Techniques}

In this paper, MATLAB codes are implemented in a Graphical user interface (GUI) for image-processing evaluation of thermal data, comparing relative thermal profiles during time in selected Regions of Interest (ROIs) in most interesting defective and defect-free zones, as showed in other works [30]. The origin of different processing techniques lies in the thermal contrast evaluation [19] and several contrasts definitions have been proposed by different authors, i. e. absolute, normalized, running or standard [19, 20], finally differential absolute contrast (DAC) [21] and interpolated differential absolute contrast approach (IDAC) [31]. The Normalized Contrast $\boldsymbol{C}_{\boldsymbol{n}}$ is considered the reference postprocessing parameter employed for pulsed thermographic data. $\boldsymbol{C}_{n}$ is introduced in image processing to reduce negative effects of reflected energy in the thermal analysis, thus providing better quantitative data [19, 32].

The normalized parameter $\boldsymbol{C}_{\boldsymbol{n}}$ is defined by as 
$C_{n}(t)=\frac{\overline{T_{d}(t)}}{\overline{T_{d}\left(t_{\max }\right)}}-\frac{\overline{T_{i}(t)}}{\overline{T_{i}\left(t_{\max }\right)}}$

With $\overline{T_{d}(t)}$ and $\overline{T_{i}(t)}$ the average temperatures in defective and defect-free ROIs of pixels at time $t$, during the cooling phase, and $t_{\max }$ the time of maximum thermal contrast [19]. The MATLAB code is applied to process the 3D matrix of thermal data, evaluating isothermal zones for a proper selection by the operator of presumed damaged areas with related non-defect zones for optimal contrast computation [19].

The Differential Absolute Contrast (DAC) parameter is based on the physical assumption that some time occur before defect visualization in thermal sequence due to travelling time of the induced thermal waves inside the component [21]. This hypothesis is developed to avoid manual selection of ROIs, assuming that in the first frames before heating time both defective and defect-free zones should produce similar thermal behaviour [20, 21]. Therefore, the thermal behaviour over time of a non-defect pixel zone could be computed considering the $1 \mathrm{D}$ analytical solution of transient heat transfer across component thickness; using 1D solution with Fourier equation for Dirac heat pulse propagation by conduction in a semi-infinite isotropic solid from surface $[33,34]$ and with assumption that initial condition is given by the reference temperature of non-defective zone for each pixel, DAC calculation is obtained by subtracting the measured temperature of nondefect zone from the estimated thermal profile of each pixel as

$\Delta T_{D A C}(t)=T(t)-\sqrt{\frac{t \prime}{t}} \cdot T\left(t^{\prime}\right)$

where $\boldsymbol{T}\left[{ }^{\circ} \mathrm{C}\right]$ is the temperature at the time $t[\mathrm{~s}]$ and $t^{\prime}$ is the time relative to a specific thermogram where no defect is visible. Generally, this processing technique provides good results for thin components (as composite parts) and for early time frames.

The statistical methods include Skewness and Kurtosis analysis, Reconstruction and derivative Techniques. In probability theory, the skewness is a common statistical method that include the third standardized moment of the probability distribution. The skewness parameter characterizes the lack of symmetry in a probability distribution of the temperature-time history; it is defined for each pixel as [35]

Skewness $=\frac{\sum_{k=1}^{N}\left(x_{k}-\mu\right)^{3}}{\sigma^{3}(N-1)}$

where $\boldsymbol{\mu}$ and $\boldsymbol{\sigma}$ are the mean and standard deviation respectively of random variable $\boldsymbol{x}$.
The Kurtosis is the fourth standardized moment of the probability distribution that measures the relative flatness of the probability distribution in the temperature-time history on each pixel. Kurtosis is given as [36]

Kurtosis $=\frac{\sum_{k=1}^{N}\left(x_{k}-\mu\right)^{4}}{\sigma^{4}(\boldsymbol{N}-1)}$

Finally, the thermal signal reconstructed (TSR) approach with derivative technique for contrast computation provide a significant sensitivity improvement of thermographic images, increase signal-to-noise performance and is claimed to reduce spatial and temporal non-uniform noise [22]. In the TSR method, time sequence of each pixel is processed as $\log -\log$ thermal response with a nth polynomial degree [37, 38]. The Equation of theoretical semi-infinite solution [33] could be transformed into logarithmic domain and expressed as [22]

$$
\begin{aligned}
\ln (\boldsymbol{T})= & \ln \left(\frac{\boldsymbol{Q}}{\boldsymbol{e}}\right)-\frac{1}{2} \ln (\pi t)=\boldsymbol{a}_{0}+\boldsymbol{a}_{1} \cdot \ln (\boldsymbol{t}) \\
& +\boldsymbol{a}_{2} \cdot[\ln (\boldsymbol{t})]^{2}+\ldots+\boldsymbol{a}_{\boldsymbol{n}} \cdot[\ln (\boldsymbol{t})]^{n}
\end{aligned}
$$

where the first term describes a constant offset, the second term represents the logarithmic decay response with a slope of $-1 / 2$ for ideal defect-free region and $\boldsymbol{a}_{0}, \boldsymbol{a}_{1}, \ldots, \boldsymbol{a}_{\boldsymbol{n}}$ are the polynomial regression coefficients. In processing-analysis, fourth and fifth polynomial orders were found to be the most effective for temporal noise reduction [17, 39], thus in the present work the authors interpolate the thermal sequence with logarithmic variables performing a least squares fit using the fifth order polynomial. Consequently, the first and the second log-time derivatives of polynomial thermal response enhanced defect detectability and signal to noise ratio, reducing negative effects caused by lateral diffusion, unless high noise content occurs [22, 40, 41].

Finally, the Principal Component Thermography (PCT) technique $[12,35,42]$ is an orthogonal linear transformation of thermal image sequences into a new coordinate system, using singular value decomposition (SVD). The acquired 3D matrix (Dim. $\mathrm{N}_{\mathrm{x}} \times \mathrm{N}_{\mathrm{y}} \times \mathrm{N}_{\mathrm{t}}$ with $\mathrm{N}_{\mathrm{t}}$ number of frames) of thermal data is reshaped into a $2 \mathrm{D}$ matrix, $\boldsymbol{A}$ (Dim $\mathrm{M} \times \mathrm{N}_{\mathrm{t}}$ with $\mathrm{M}=\mathrm{N}_{\mathrm{x}} \times \mathrm{N}_{\mathrm{y}}$ ), where the columns and rows contain the spatial and temporal, and computed as

$A=U D V^{T}$

where $\boldsymbol{U}$ is orthogonal matrix of dimension $\mathrm{M} \times \mathrm{N}$ that contains a set of empirical orthogonal functions (EOFs), describing spatial variations in matrix's columns [24]. The variable $\boldsymbol{D}$ is a diagonal matrix (Dim. $\mathrm{N} \times \mathrm{N})$ comprising the absolute values of the eigenvalues (singular values) of 
matrix $A$. The variable $V^{T}$ is the transpose matrix (Dim. $\mathrm{N} \times \mathrm{N}$ ) of the orthogonal matrix where the rows represent the principal components (PCs) characteristic of "in time behaviour" and associated to defect depth estimation [41, 43].

In previous works, the authors proposed new thermal Image-mapping technique [denoted as Local Boundary Contrast (LBC)] [26] to increase a defect contrast parameter with damage zone surrounding area and to reduce negative effects induced by non-uniform heating, providing an improvement of defect shape and extension visibility [27, 30]. This thermal contrast evaluation combines the pros of DAC approach to remove the manual selection of reference non-defective zone for relative contrast computation for each given defect, together with characteristics of Digital Image Correlation (DIC) approach [44], to automatically elaborate thermal image and correlating a selected ROI to a reference ROI through automatic digital processing of the whole thermal data [30]. Therefore, at a given time $t$, the computation of proposed absolute local contrast, denoted as $\boldsymbol{C}_{\boldsymbol{L B C}-\boldsymbol{I}(\boldsymbol{i}, \mathrm{j})}^{\mathrm{std}}\left[{ }^{\circ} \mathrm{C}\right]$ is evaluated for each pixel of general location $[i, j]$ as

$$
\begin{aligned}
& C_{L B C-I(i, j)}^{\text {std }}(t)=\left|v T_{L B C(i, j)}(t)\right|=\left|\overline{N_{R O I(i, j)}(t)}-\overline{I_{R O I(i, j)}(t)}\right| \\
& =\mid \frac{1}{2 p+1} * \sum_{k=i-p}^{i+p}\left[\frac{1}{2 p+1} * \sum_{w=j-p}^{j+p}\left(T_{N_{(k, w)}(t)}\right)\right] \\
& -\frac{1}{3} \sum_{z=i-1}^{i+1}\left(\frac{1}{3} * \sum_{v=j-1}^{j+1} T_{I_{(z, v)}(t)}\right) \mid
\end{aligned}
$$

where $\overline{I_{\boldsymbol{R O I}(i, j)}(t)}$ and $\overline{N_{R O I(i, j)}(t)}$ represents the average temperatures of a subset matrix (Dim. $3 \times 3$ ) and of its neighbourhood matrix (Dim. $p \times p$, where $p>3$ ), respectively. The new approach provides processed contrast maps that maximize contrast values when processing ROIs incorporate the pixels lying on defect boundaries, leading to better display local contrast variations, clearly recognizing flaw's shape. Therefore, the LBC technique is a sort of spatial filtration as a high-frequency (gradient) spatial filter which should maximise defect border thermal response, hence improving also signal-to-noise ratio.

The proposed LBC method provides processed contrast map at a given time (as DAC approach), but a useful third and alternative approach could be employed to compress the information contained in the 3D thermal sequence into a single image method (as seen in statistical methods based on the third order, the skewness, and fourth order, the kurtosis) $[35,36]$. Based on the third approach, the new LBC II proposed technique should be performed to also provide a time filtration and the computation of new contrast $C_{L B C-I(i, j)}^{\text {std }}$ for each pixel of general location $[i, j]$ follows the equation:

$$
\begin{aligned}
& C_{L B C-I I(i, j)}^{\text {std }}=\left|\Delta T_{L B C(i, j)}\right| \\
& \quad=\left|\sum_{t=t_{\max }}^{t_{\text {end }}} \frac{1}{\left(t_{\text {end }}-t_{\max }\right)} \cdot \overline{N_{R O I(i, j)}(t)}-\sum_{t=t_{\max }}^{t_{\text {end }}} \frac{1}{\left(t_{\text {end }}-t_{\max }\right)} \cdot \overline{I_{R O I(i, j)}(t)}\right|
\end{aligned}
$$

where $\left(t_{\text {end }}-t_{\max }\right)$ represents the cooling phase of the thermal acquisition. The implemented MATLAB algorithm represents a suitable alternative to improve the image-processing for automatic defect detection in terms of computation time and easy post-processing analysis, even that $\boldsymbol{C}_{\boldsymbol{L B C} \boldsymbol{C} \boldsymbol{I I}(\boldsymbol{i}, \mathrm{j})}$ implies longer computing times.

\section{Results and Discussion}

The data results are post-processed employed a MATLAB Graphical user interface (GUI) for frames re-sizing from 3D thermal matrix to remove the negligible corner of pixels if the windowing command from camera is not available. At a given time $t$, the proper thermal parameters in selected ROIs are evaluated in similar way for normalized contrast [19]; in addition, a normalized contrast parameter is here introduced as:

$k_{n}(t)=\frac{\overline{k_{d}(t)}}{a b s\left(k_{d \_ \text {max }}\left(t^{\prime}\right)\right)}-\frac{\overline{\mathrm{k}_{\mathrm{i}}(\mathrm{t})}}{\operatorname{abs}\left(\mathrm{k}_{\mathrm{i} \_ \text {max }}\left(t^{\prime \prime}\right)\right)}$

where $\boldsymbol{k}_{\boldsymbol{n}}(t)$ represents the difference between average values in defective $\overline{k_{d}(t)}$ and undamaged $\overline{k_{i}(t)}$ ROIs and normalized with respect to relative maximum values. Consequently, the computation limit of previous equation clearly occurs in case processing methods provided one single map of results (as skewness, kurtosis, and LBC-II approaches); for these cases, the resulting image computed normalized contrast can be easily given by difference of two ROIs values from the same map, as in the follows:

$k_{n}=\overline{k_{d}}-\overline{k_{i}}$

\subsection{Contrast Methods Results}

In Fig. 4a, a raw thermogram is selected and the delaminated area after 10 cooling seconds and other defective zones are already visible; five defects are selected in the map, providing a suitable input for manual selection of ROIs for clearly detectable defects and for undamaged zones. Most interesting defective areas (ROI-1, ROI-3, ROI-5, ROI-7, and ROI-9) and defect-free zones (ROI-2, ROI-4, ROI-6, ROI-8, and ROI-10) are Due to thermal wave propagation inside the element, with the temperature profile recorded on excited surface starts to decay, following diagrams as shown in Fig. 4b. However, the analysis of 


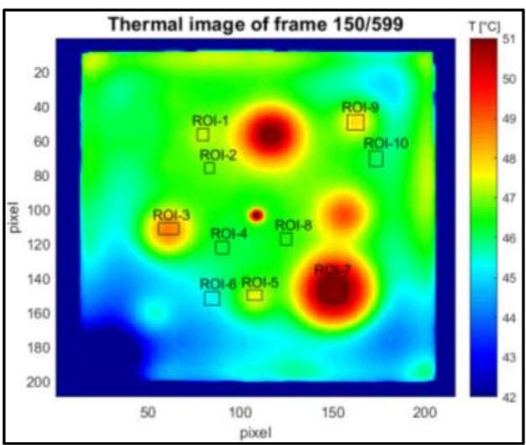

(a)

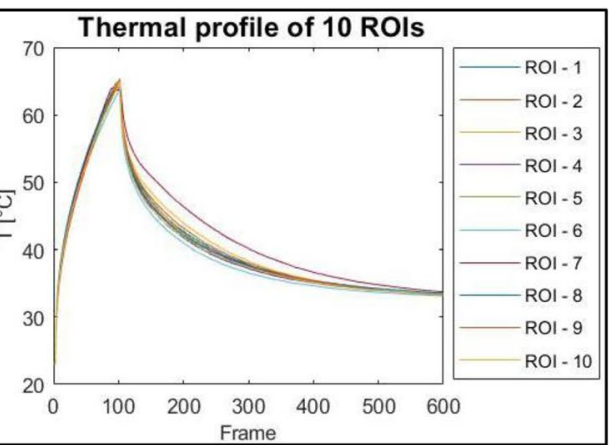

(b)

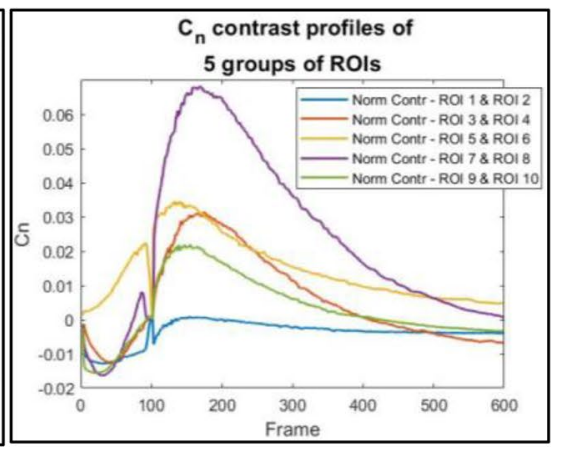

(c)

Fig. 4 a Raw thermal map after 10 cooling s, b thermal profiles of selected ROIs and $\mathbf{c} C_{n}$ contrast profiles of 5 couples of ROIs of reference plate

thermal profiles seem to offer difficult comparative evaluation between defective and undamaged zones, as well as between acceptable and critical flaws; therefore normalized profiles should be analysed, as computed on the basis of Eqs. 1, 9 and 10. As presented in Fig. 4c, the typical trends of processed normalized contrast $C_{n}$ are illustrated for selected spots, where maximum peaks of defects ROI-7 and ROI-8 provide a contrast value of one order of magnitude significantly higher than maximum peak related to smaller defect (couple ROI-1 \& ROI-2 for example).

The DAC approach is the second contrast method, and the composite fabric seems to be highlighted on the edge of the plate in the DAC map, as shown in Fig. 5a. the flaws in ROI-5 and ROI-9 seem to be slightly distinguished, while the smaller defect ROI-1 does not appear clearly detected. Since DAC method provides a contrast map at each studied time frame, the choice of suitable frame to analyse could be done by a preventive analysis of the profile shapes of the comparable sets of ROIs previously indicated, as shown in Fig. $5 b$.
In the second CFRP component, after one second of cooling (as seen in Fig. 5c), it is immediately clear that two delamination zones (indicated as ROI-1 and ROI-3) appear, exhibiting the maximum $C_{n}$ values, as reported in Fig. 6a; the presence of artificial central cut seems not to disturb the uniform heating pattern and Fig. $6 \mathrm{~b}$ reports the output profile of the DAC parameter at the same time interval for the same couples of ROIs, where the delaminations produce a slightly higher contrasts than related thermal profile contrast, as observed in Fig. 6c.

On the other hand, Fig. 7a and c display example raw maps of the two-flat carbon-epoxy panels, which were improperly laminated with lower manufacturing pressure during curing. A widespread-porosity could be identified in both flat-panels by different thermal scale; however, the presence of a diffused voids provides a difficult selection of proper and different ROIs (as shown in Cn profiles of Fig. 7b) for the comparative analysis of most used processing methods to be compared. At the contrary, the processing Skewness, Kurtosis and LBC-II methods are

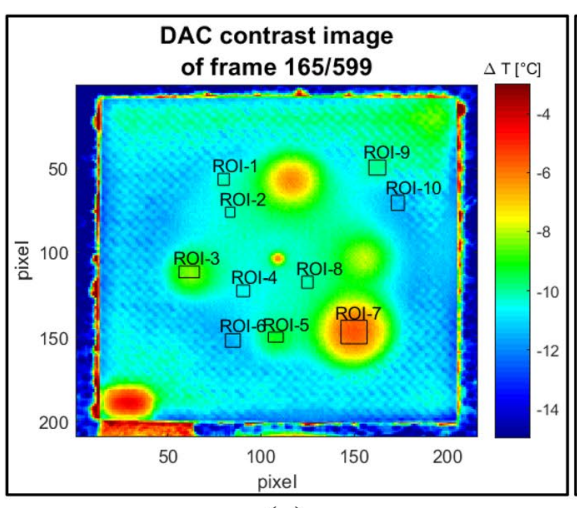

(a)

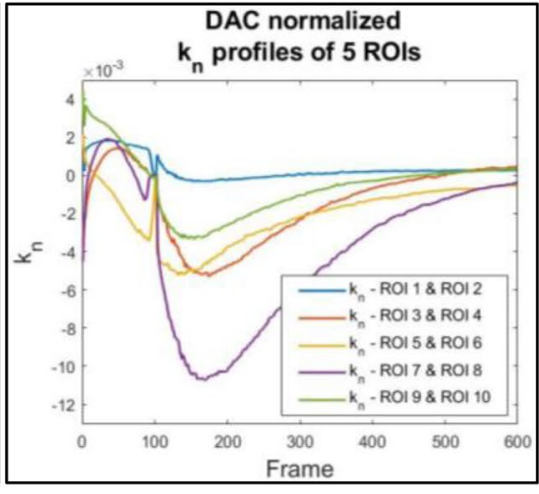

(b)

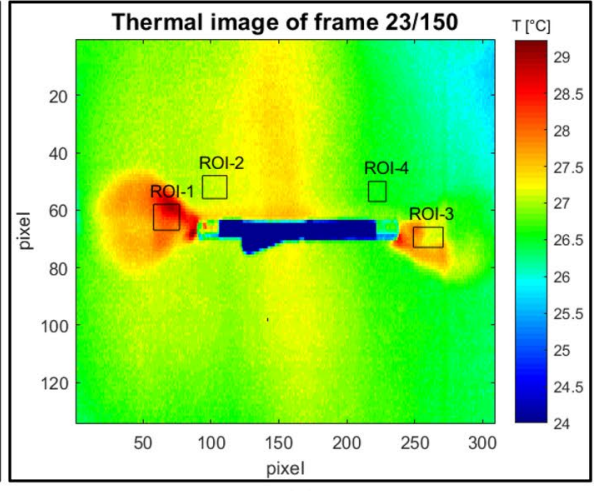

(c)

Fig. 5 a DAC map after 12 cooling $\mathrm{s}$ and $\mathbf{b} k_{n}$ profiles of DAC results of reference plate; $\mathbf{c}$ Raw thermal map of multi-stringer element after 1 cooling s 
selected as suitable best procedures for these CFRP panels, due to their defects' detection much more straightforward, also preferred because a single processed map should be analysed.

\subsection{Statistical Methods Results}

From Fig. 8a-c, the evaluation of TSR maps and derivative profiles for each ROI was also able to reveal the defect relative maximum peaks, using a fifth order polynomial fitting and reducing time induced noise; maximum value of $k_{n}$ contrast will appear in TSR normalized difference of

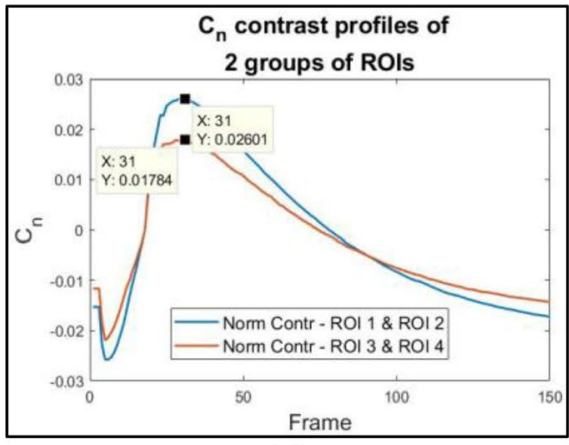

(a)

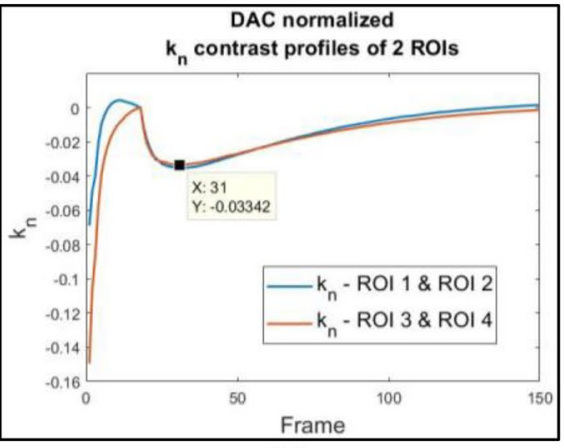

(b)

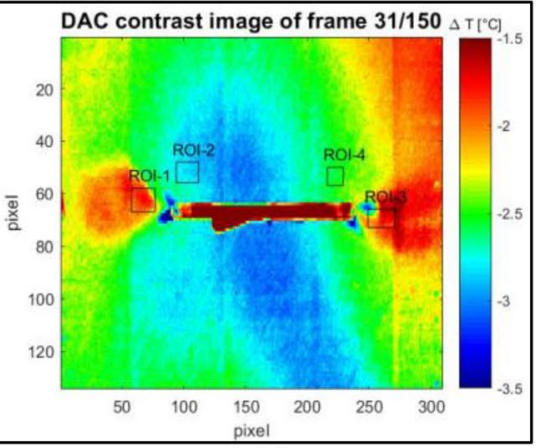

(c)

Fig. 6 a Normalized contrast $C_{n}$ and $\mathbf{b} k_{n}$ profiles of DAC results of 4 ROIs; (c) DAC map after 1 cooling s of multi-stringer

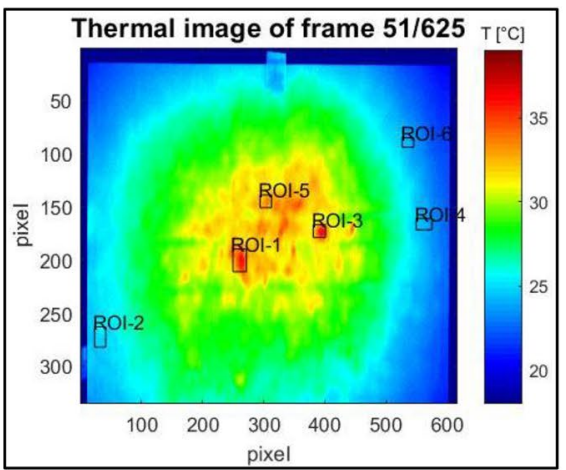

(a)

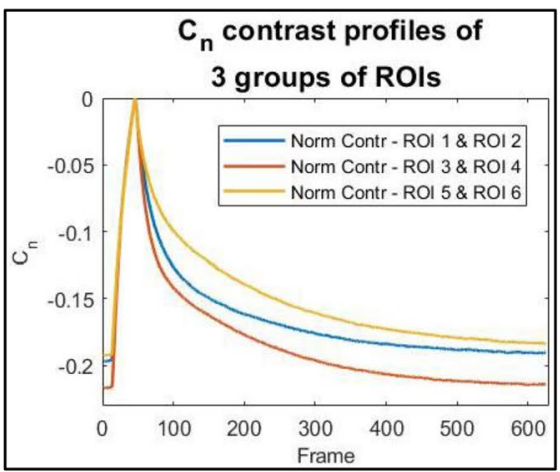

(b)

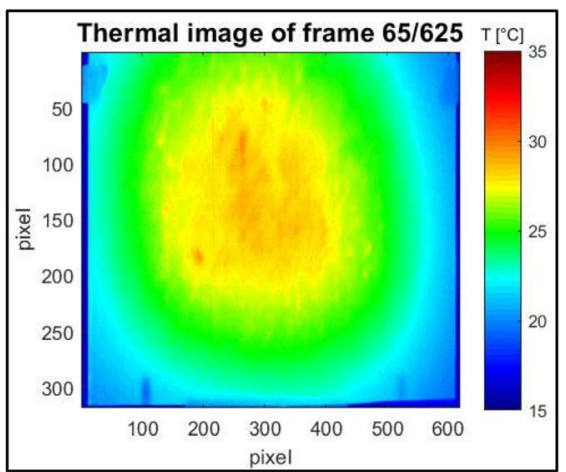

(c)

Fig. 7 a Thermal map and $\mathbf{b}$ normalized contrast $C_{n}$ profiles of ROIs in upper sector for flat Panel-1; $\mathbf{c}$ thermal map in lower sector for flat Panel2

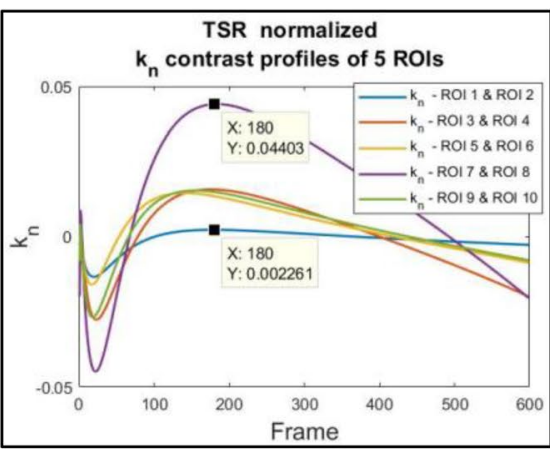

(a)

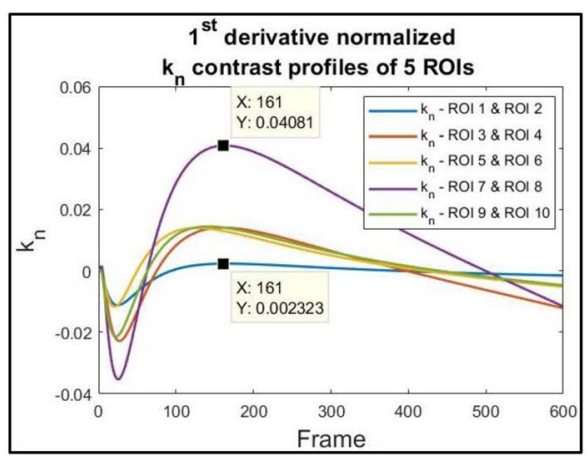

(b)

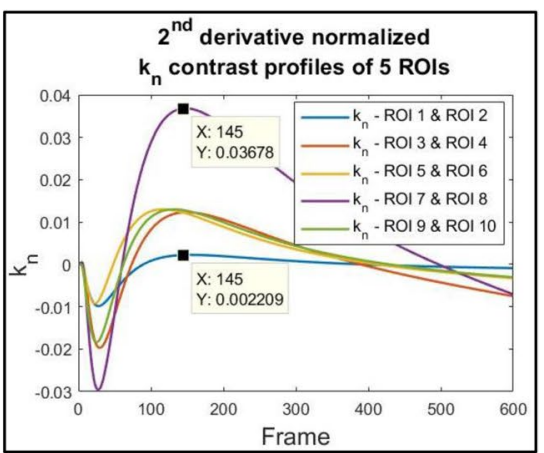

(c)

Fig. 8 a TSR, b 1s derivative and $\mathbf{c}$ 2nd derivative normalized $k_{n}$ profiles for regions of interest (ROIs) of reference plate 
selected ROIs at few cooling frames after the initial first and second derivative trends, as in the example in Fig. 8a.

The TSR approach should help to define defect location in few unique images, computing sensitivity to first and second derivative data in images, also capable to detect carbon-fiber positioning in laminate, overcoming a detectability threshold of previous DAC method (Fig. 4b). Although the good quality of TSR and derivatives maps, the smallest defects result to be hardly to be perceived. Nevertheless, the relative TSR and derivative images are presented in Fig. 9a-c, showing that good defect contrast enhancement and noise reduction proved to be beneficial in effective TSR processing of the CFRP reference plate.

Furthermore, skewness and kurtosis images provide single processed maps, where most of distinguished defects appear consistently and the composite fabric seems not to cause a noticeable disturbance for inspected flaws, as shown in Fig. 10a and b. A better contrast is highlighted in the kurtosis image, as in Fig. 10b.

For the multi-stringer element, similar trends seem not appear using TSR method and 2nd normalized derivative profiles of the two significant ROIs in multi-stringer panel, as shown in Figs. 10c and 11a; normalized difference of TSR data and derivative profiles will exhibit maximum values during cooling phase, hence highest contrast values are easily provided by TSR approach. As seen instead in raw and DAC computed maps (Figs. 4c, 5a), some disturbance of non-uniform cooling behaviour is to be observed in the central zone on simulated damage, as reported in Fig. $11 \mathrm{~b}$. The TSR image is evaluated after 3.2 cooling seconds when maximum value of $k_{n}$ contrast appears in TSR normalized difference of selected ROIs.

In Figs. 11c and 12a, both statistical methods based on third and fourth standardization are presented much more straightforward and the detection of delamination zones is showed with less blurred edges, reducing the potential errors in assessing defective areas; in skewness and kurtosis maps, the central left and right stiffeners start to appear through thickness at the back side, at a depth of more than $4 \mathrm{~mm}$, whilst non-uniform cooling related signs are normally only faintly observable in the raw data for DAC and TSR maps. Figures $11 \mathrm{c}$ and $12 \mathrm{a}$ describe the third and the fourth

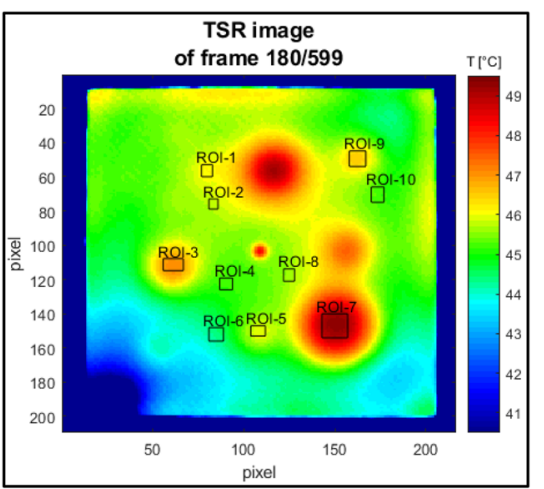

(a)

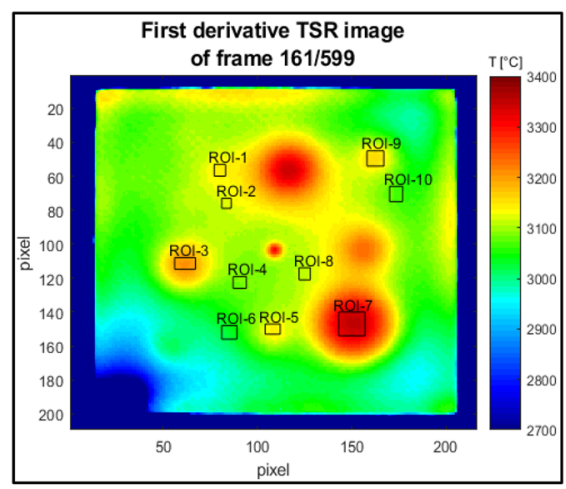

(b)

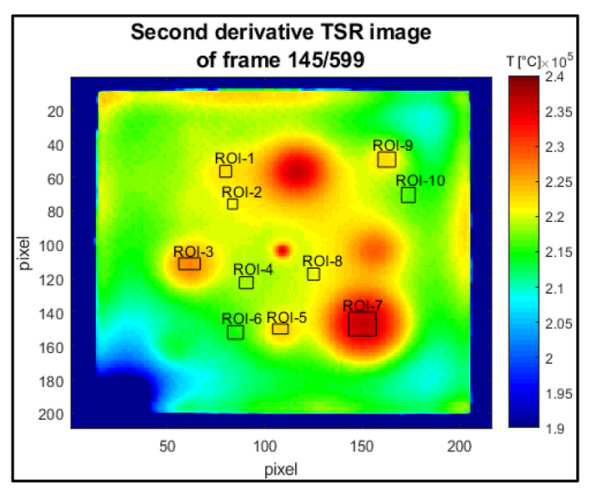

(c)

Fig. 9 a TSR, b first derivative and $\mathbf{c}$ 2nd derivative maps with ROIs of reference plate

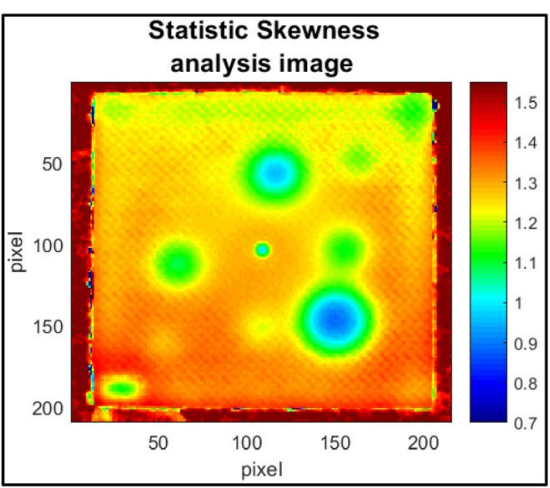

(a)

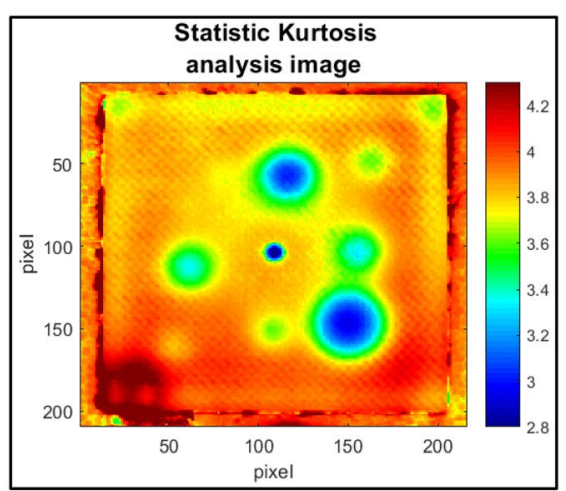

(b)

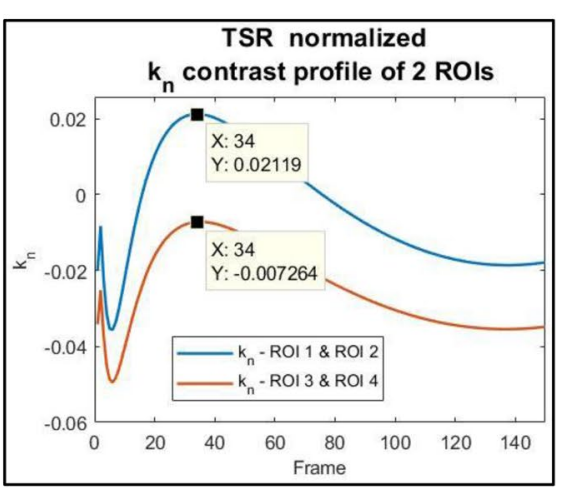

(c)

Fig. 10 a Skewness and $\mathbf{b}$ Kurtosis maps of reference plate; $\mathbf{c}$ TSR normalized $k_{n}$ profiles of ROIs for multi-stringer panel 
standardization of probability distribution and seem to be very similar, therefore the kurtosis obtained map seem to more maximize the contrast of stringers and delaminated areas with respect to skewness map. As general conclusion, statistical kurtosis and skewness are found to be efficient techniques, reducing the processing time and processed data, to justify their choice to process the raw thermograms in case of CFRP Panels 1 and 2; interesting and accurate results are achieved.

In Figs. 12b and 13c, diffused porosity on upper and lower sectors of both panels is inspected and could now also be easily displayed reducing the negative effect on

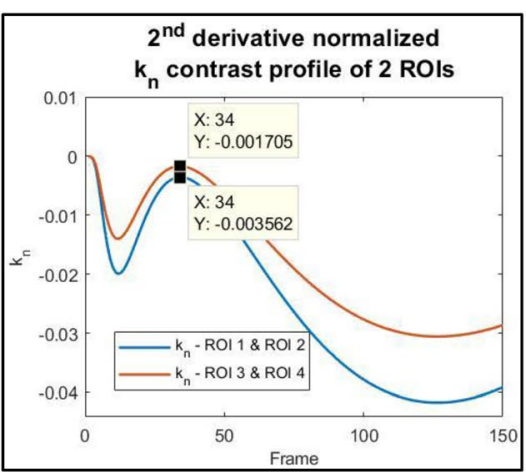

(a)

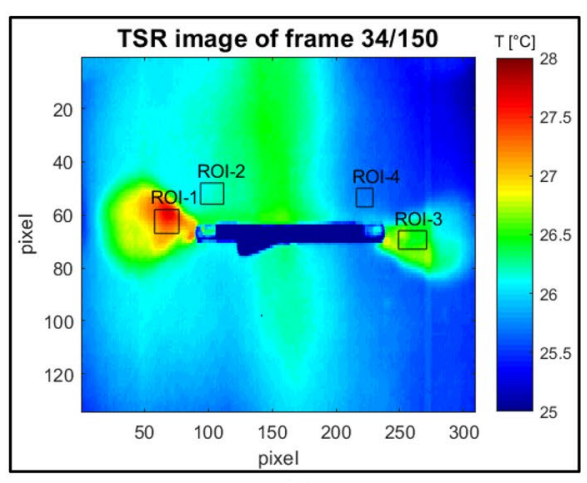

(b)

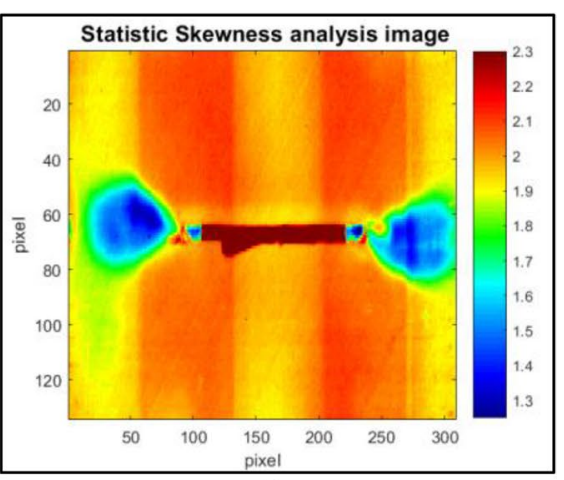

(c)

Fig. 11 a 2nd derivative normalized $k_{n}$ profiles of ROIs, b Example of TSR and $\mathbf{c}$ Skewness maps for multi-stringer panel

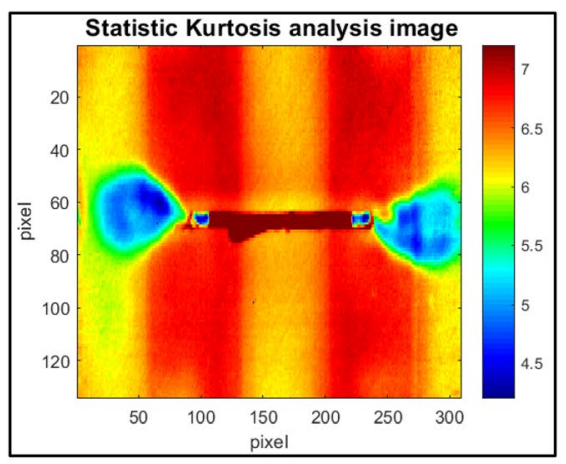

(a)

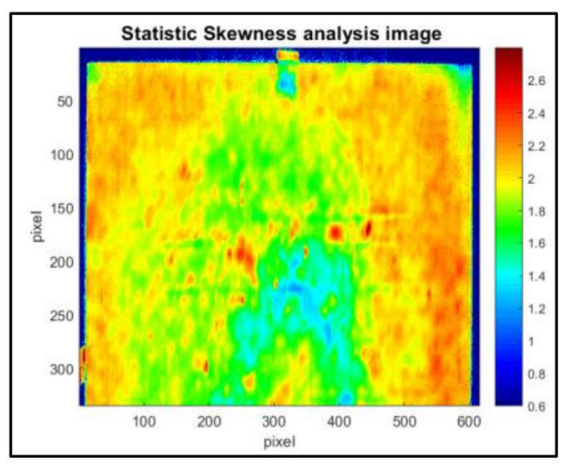

(b)

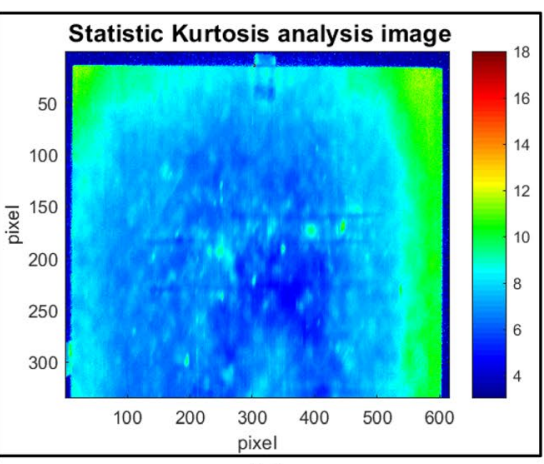

(c)

Fig. 12 a Example of Kurtosis map of multi-stringer panel; b Skewness and c Kurtosis maps for upper sector of Panel-1

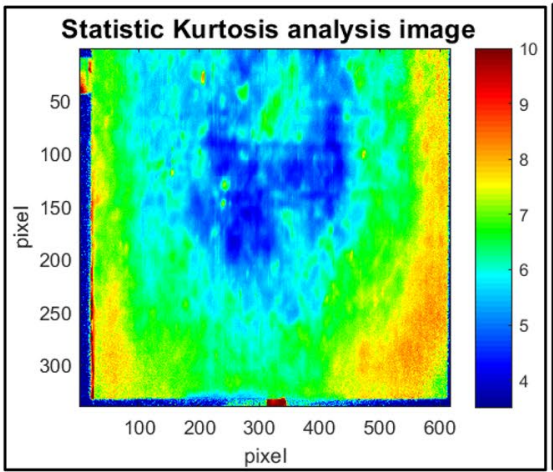

(a)

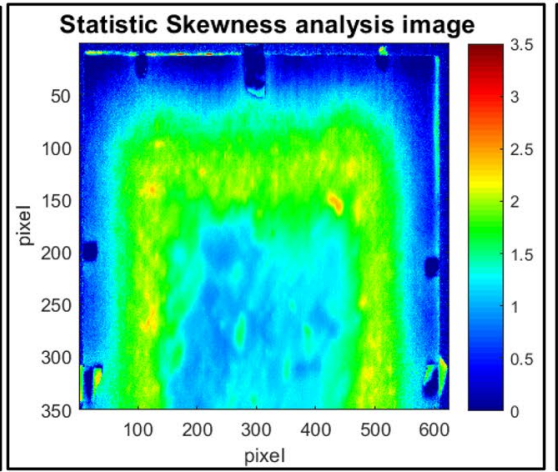

(b)

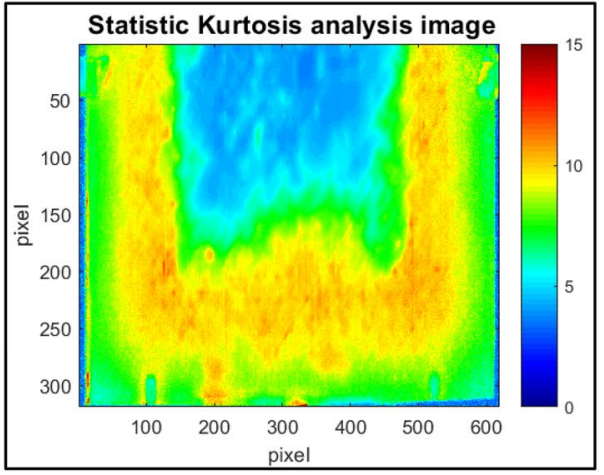

(c)

Fig. 13 a Kurtosis map for lower zone of Panel 1; b Skewness for upper sector and $\mathbf{c}$ Kurtosis maps for lower zone of Panel 2 
non-uniform heating which is difficult to reduce during experimental set-up. As expected, a widespread porosity is observed in all inspection of CFRP panels and the lower manufacturing pressure of panel 1 seems to introduce larger number of internal voids than panel 2 obviously, even that the latter has lower thickness and is laminated with four times greater pressure (as reported in Table 1). Thus, since data compression and interpretation represent the main interest for these processing techniques, but a fast simplified post-processing analysis of unique processed map, containing all the relevant information, marks the robust advantage and huge defect representation over the basic thermal 3D sequence analysis.

\subsection{PCT and EOF Results}

As seen in Eq. 6, the PCT processing method rearranges the input three-dimensional matrix A to produce $\mathrm{EOF}$ and $\mathrm{PC}$ images sequences; the first few EOFs here described show large variability in the thermal sequence, as shown in $14 \mathrm{a}$ [30]. The analysis of EOF profiles shows an evident data variability of all $k_{n}$ profiles in the case of 5 selected ROI couples, showing alternatively both positive and negative contrast values, maximized generally in the first frames, but identifying defects in optimal way, as the 2nd and 3rd EOFs maps highlight respectively in Fig. 14b and c.

In Figs. 14b and 15a, the fabric details of first sub-surface ply can be also detected and the local disturbance of CFRP fabric could be observed around defects and the edges' indication is hardly blurry, as seen previously in DAC map.

In Fig. 15b, the PC normalized curves present an evident different trend with respect to EOF sequences, seen in the Fig. 14a and provide lower values of normalized contrast peaks than the EOF values. Therefore, the PCT map after 11,4 cooling seconds of frame 159 is selected because seems to clearly distinguish the defect edges, reducing the negative effects of fabric lay-up contrast, as shown in Fig. 15c.

In addition, enhancing defect detection and shape definition represents the main advantages of PCT approach; normalized profiles of EOF and PC contrasts for the selected ROIs with the reference plate, in case of selected ROI-1 and ROI-5 examples suggest a suitable frame choice of

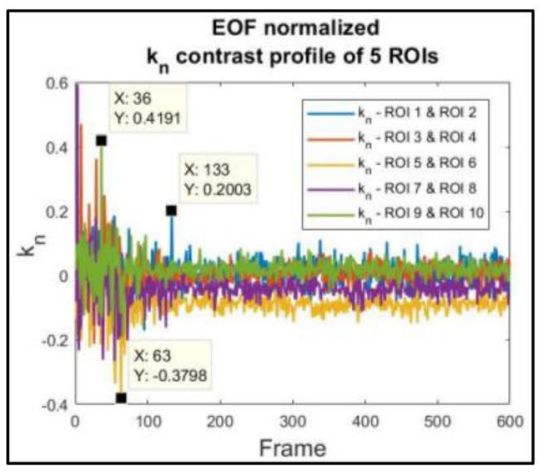

(a)

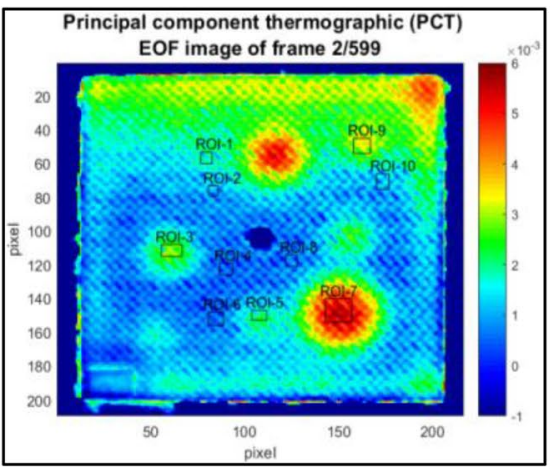

(b)

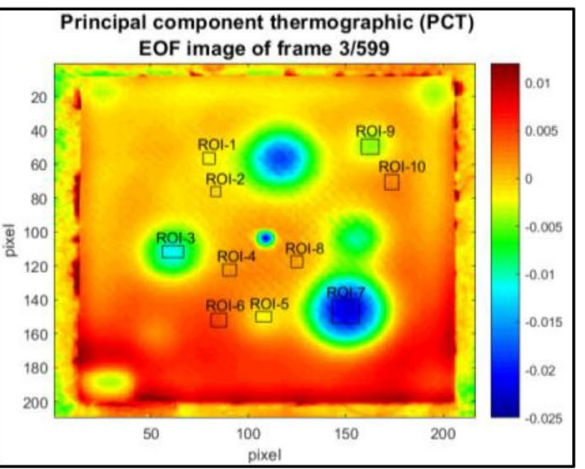

(c)

Fig. 14 a EOF normalized $k_{n}$ profiles of couples of ROIs, $\mathbf{b} 2$ nd and $\mathbf{c} 3 \mathrm{rd}$ EOFs maps for reference plate

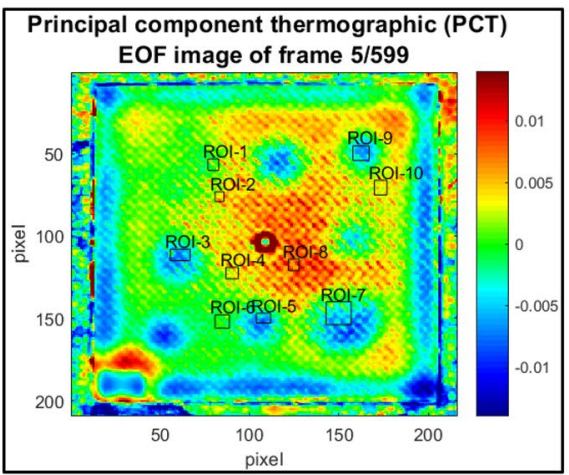

(a)

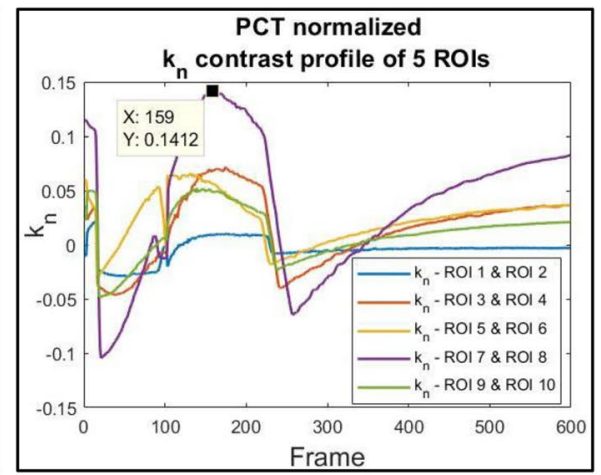

(b)

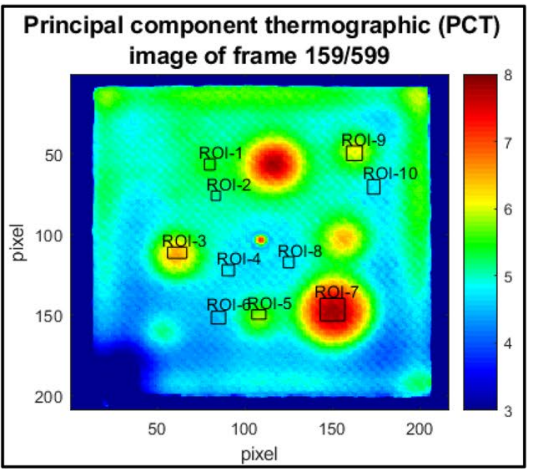

(c)

Fig. 15 a 5th EOFs map, $\mathbf{b}$ PCT $k_{n}$ profiles of ROIs' couples and $\mathbf{c}$ PCT map after 11,4 cooling s for reference plate 


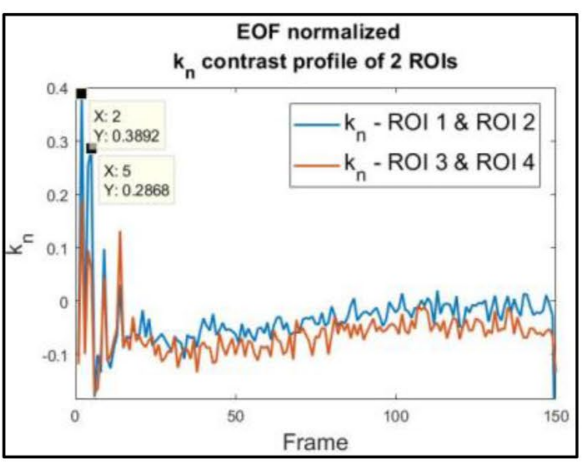

(a)

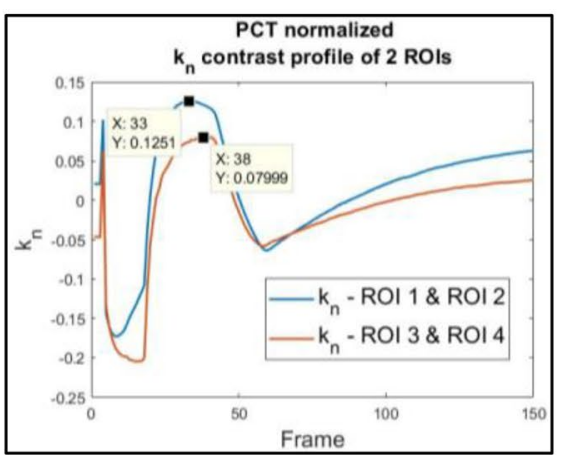

(b)

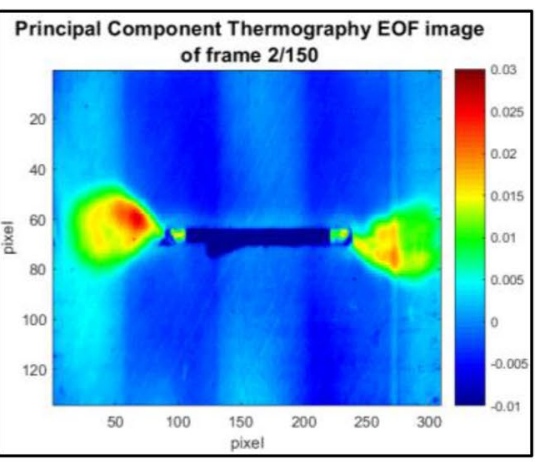

(c)

Fig. 16 a EOF and $\mathbf{b}$ PC normalized $k_{n}$ profiles of couples of ROIs and $\mathbf{c} 2$ nd EOF map for multi-stringer element

processed maps, where the normalized difference between defective and undamaged zones seems to be emphasized.

The same procedure is employed for multi-stringer element and normalized profiles of two delamination zones are reported in Fig. 16a and b, where the EOF and PCT normalized $k_{n}$ contrast is displayed for the two delaminated areas, decreasing rapidly after few frames; hence, as the capability of defect detection is limited to first frames. Despite the EOF results achieved for the reference plate, the EOF map in the Fig. 16c recorded in the $2 / 150$ frame provides good results in terms of defect boundary shape and backside stiffeners visibility. In the same EOF map, foible indications of fiber orientation could be observed with PCT analysis, showing that eventual presence of very small defect below first layers would be detected.

The EOF map of Fig. 17a at frame 5 seems to offer only a confused indication for both damaged areas, despite the stiffeners edge are still evident. In a later frame at 3 cooling seconds, both damaged zones start to become clearly visible, as reported in Fig. 17b. The presented results of PCT approach using EOF processing show, according to our opinion, an optimal sensitivity to defect detection, since more detailed features are displayed.

\subsection{LBC-I and LBC-II Results}

The LBC methods with LBC-I and LBC-II elaboration are discussed finally in this paper; in the same way of DAC approach, the processed outputs of proposed methods provide special innovative contrast maps capable to enhance defect detectability in terms of flaw boundaries. As shown in Fig. 18a, the LBC-I normalized profiles of various ROIs maximizes defect contrast with its surrounding area of all selected ROIs in reference plate. The contrast distributions give maximum normalized contrast values of comparable level with EOF results and showing more defined profiles.

The smaller defects for example present a maximum normalized LBC-I very high contrast difference of 0.832 after 5.5 cooling seconds in frame 129; in Fig. 18b, the relative LBC-I map seems to increase the detectability of smaller defects around $5 \mathrm{~mm}$ diameter, reducing the negative effects

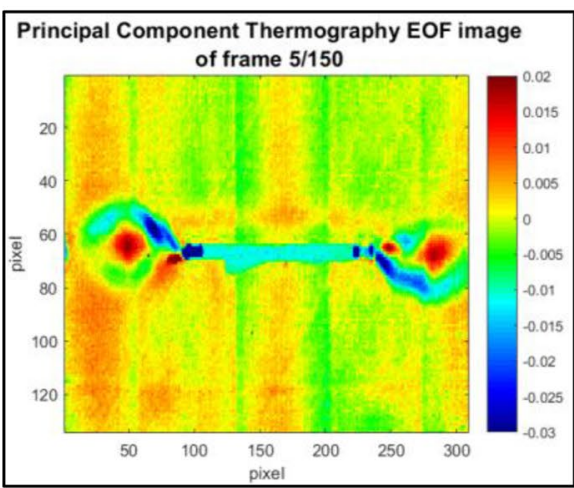

(a)

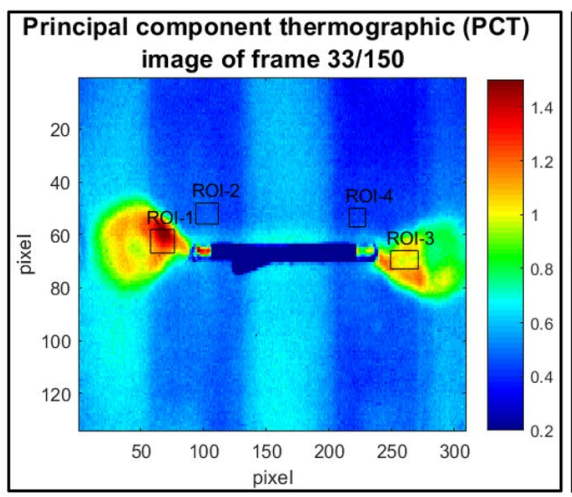

(b)

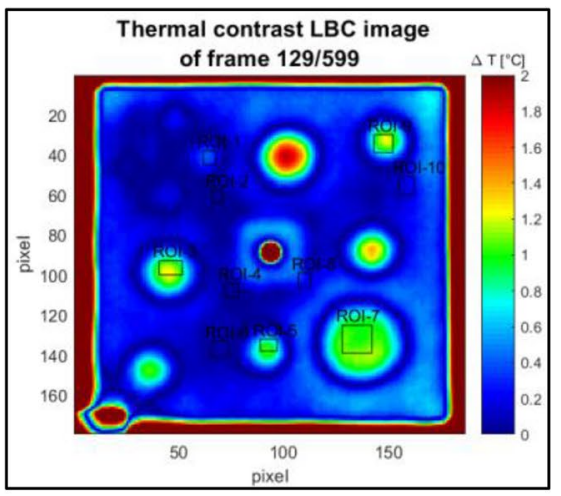

(c)

Fig. 17 a 5th EOF and $\mathbf{b}$ PCT maps after 3 cooling s of multi-stringer and $\mathbf{c}$ LBC-I map after 5.5 cooling s for CFRP plate 


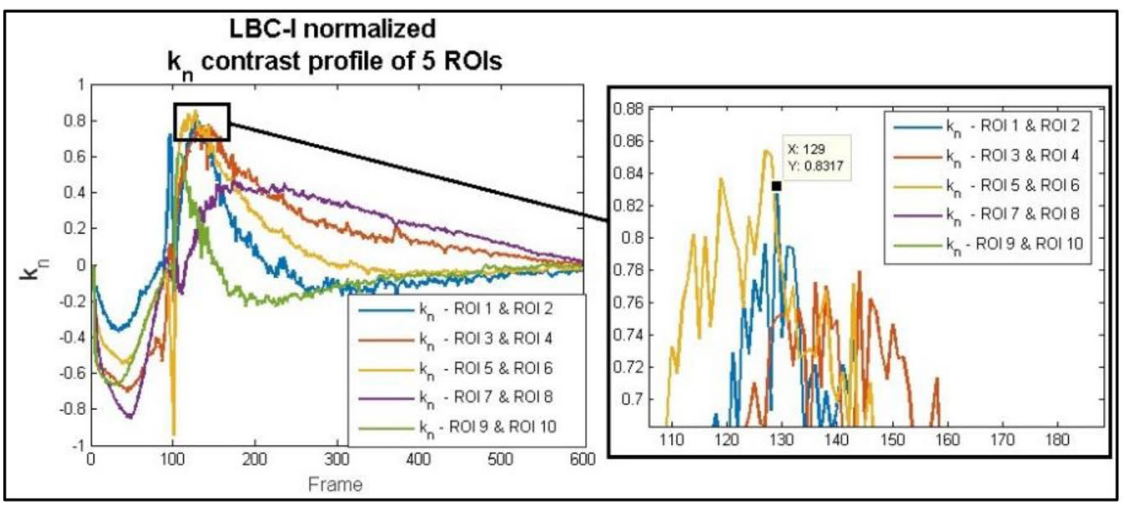

(a)

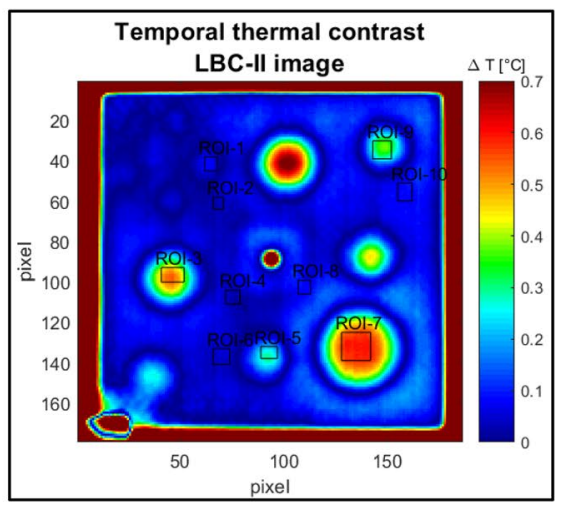

(b)

Fig. 18 a LBC normalized $k_{n}$ profiles of selected ROIs and $\mathbf{b}$ LBC-II of reference plate

Table 3 Comparative analysis between difference of average parameter values of ROI couples for reference plate

\begin{tabular}{lllll}
\hline CFRP component & Couple of ROIs & Skewness & Kurtosis & LBC-II \\
\hline Reference plate & ROI-1 \& ROI-2 & -0.022 & -0.027 & 0.046 \\
& ROI-3 \& ROI-4 & -0.194 & -0.446 & 0.459 \\
& ROI-5 \& ROI-6 & -0.115 & -0.323 & 0.198 \\
& ROI-7 \& ROI-8 & -0.368 & -0.819 & 0.495 \\
& ROI-9 \& ROI-10 & -0.116 & -0.284 & 0.240 \\
\hline
\end{tabular}

due to fiber fabric direction signals, which may hide other detailed defect data.

The proposed algorithm is based on the principle that computed temperatures around an inspected spot tend to reach similar values when location corresponds to defect border, leading to contrast values being displayed with minimum values on contrast maps, clearly distinguishing the damage's edge. However, a faster defect detectability could be provided reducing the number of frames. Therefore, based on the previous principles, the second LBC approach (denotated LBC-II) has been introduced when only a single map is post-processed by 3D thermal matrix, as seen in statistical methods based on standardization. As shown in Fig. 18b, this approach provides a processed contrast map comparable with LBC-II image, removing the analysis of ROIs profile for frame selection. In Table 3, a comparative analysis between difference of average parameter values of ROI couples is reported for reference plate. The LBC-II provides an evident maximum absolute contrast value for smaller defect (ROI-I), highlighting the defect detectability of smaller flaws. The other average values seem to be lower than the relative Kurtosis ones, but higher than the relative Skewness ones.

In the case of multi-stringer element, the Fig. 19a shows similar trends for normalized LBC-II profiles of delamination damage; the damage's edges clearly appear in the selected thermogram after 3.8 cooling seconds as seen in Fig. 19b. However, the presence of the central cut seems to provide very high surrounding contrast around central zone both in the LBC-I and LBC-II maps as shown in Fig. 19b and $\mathrm{c}$.

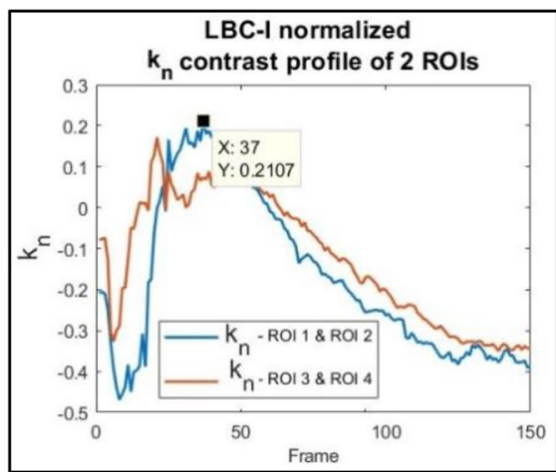

(a)

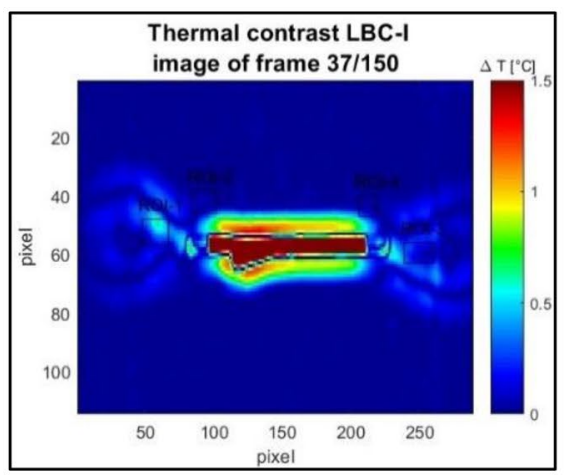

(b)

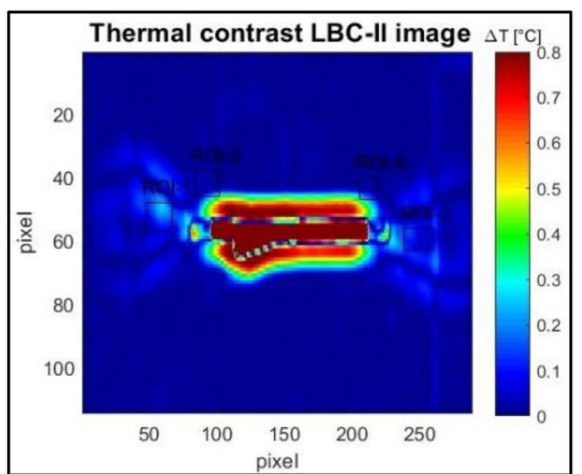

(c)

Fig. 19 a LBC normalized $k_{n}$ profiles of selected ROIs, b LBC-I and $\mathbf{c}$ LBC-II maps of multi-stringer panel 


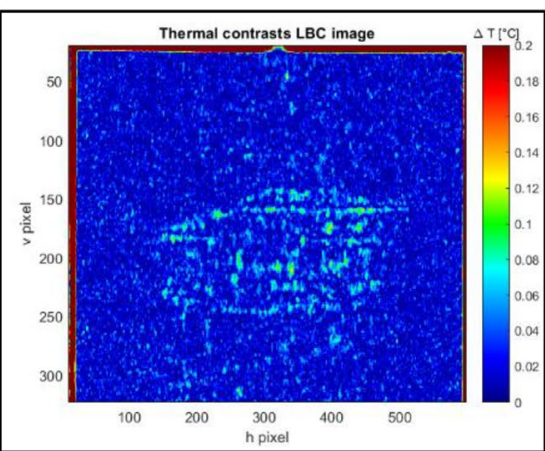

(a)

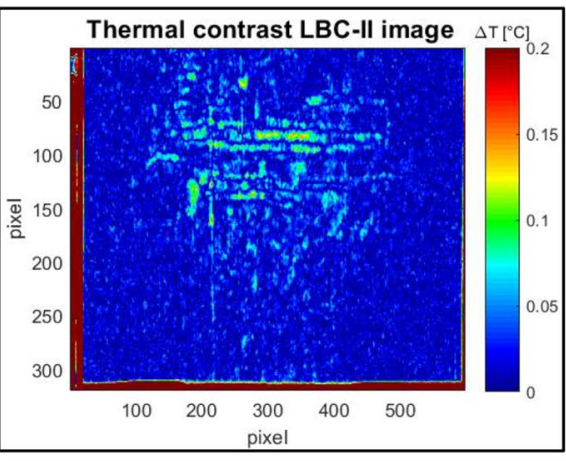

(b)

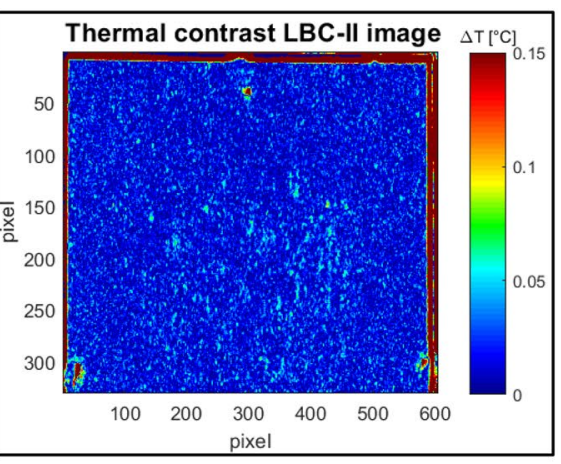

(c)

Fig. 20 a LBC-II maps of upper and $\mathbf{b}$ lower sectors of panel 1; $\mathbf{c}$ LBC-II map of upper sector of panel 2

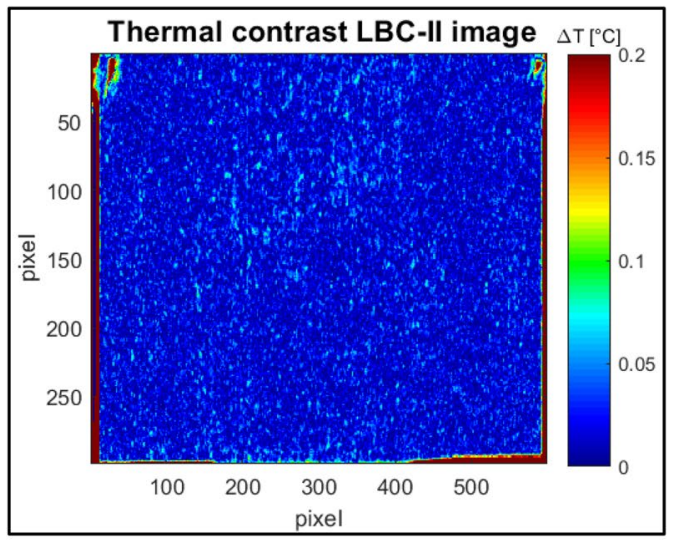

(a)

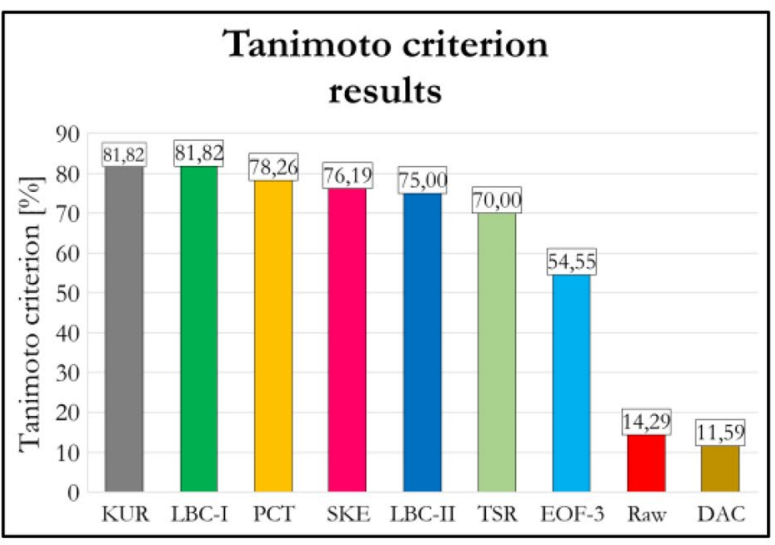

(b)

Fig. 21 a LBC-II map of lower sector of panel 2; $\mathbf{b}$ diagram of Tanimoto criterion results for reference plate

Finally, thermal acquisition of two CFRP panel are processed employing LBC-II approach, to reduce the noise effects and possible non-uniform heating interference, as reported in Figs. 20a and 21a. Diffused imperfections could be seen in all inspected surfaces and this widespread damage creates an evident negative effect in terms of defect inspection. As expected, the Panel-1 results more damaged with respect to the other Panel-2, due to different manufacturing conditions, as shown in Fig. 20a and b. However, the correct defect identification seems to be almost complex without a foreknowledge on the part and its defects.

\subsection{Comparative Analysis of Post-processing Results}

The goodness quantification of different processing results is proposed employing the Tanimoto Criterion and signal to noise ratio (SNR) evaluation.

\subsubsection{Tanimoto Criterion}

The Tanimoto criterion $[28,45]$ is employed on selected processed images to compare the defect detectability of postprocessing methods. The Tanimoto criterion is given as

$T_{C}=\frac{N_{r . d .}-N_{m . d .}}{N_{r . d .}+N_{f . d .}}$

where $N_{r . d .}, N_{m . d .}, N_{f . d .}$ are respectively the number of real, missed and false reading defects detected with different processing methods.

Therefore, for reference plate, specific thermograms selected are selected for each method because it corresponds to the best visibility time for a maximum number of defects $[28,45]$. The capabilities of the different signal processing methods (DAC, PCT, TSR, LBC, Kurtosis and Skewness) are compared for qualitative and quantitative defect detection, showing a detection efficiency around 11 to $82 \%$ in terms of Tanimoto criterion. As shown in Fig. 21b, the 
Table 4 Signal to noise values for elaborated maps of reference plate

\begin{tabular}{llllllllllll}
\hline Defective zones & \multicolumn{1}{l}{ SNR $[\mathrm{dB}]$} & \multicolumn{10}{l}{} \\
\cline { 2 - 11 } & DAC & TSR & 1st Der & 2nd Der & EOF 2 & EOF 3 & PCT & LBC-I & SKEW & KURT & LBC-II \\
\hline D7 / ROI-1 & -9.63 & 37.73 & 40.51 & 33.92 & 16.12 & 18.45 & 32.31 & 45.96 & 22.42 & 21.51 & 25.02 \\
D3 / ROI-3 & 36.56 & 42.89 & 42.24 & 43.97 & 26.36 & 23.23 & 39.68 & 40.60 & 40.43 & 38.99 & 40.42 \\
D2 / ROI-5 & 38.48 & 42.15 & 40.52 & 38.79 & 23.28 & 22.28 & 34.55 & 38.31 & 36.79 & 40.11 & 37.83 \\
D1 / ROI-7 & 49.72 & 59.36 & 57.11 & 55.00 & 30.37 & 24.01 & 33.13 & 39.73 & 49.05 & 49.86 & 44.10 \\
D5 / ROI-9 & 28.49 & 50.44 & 42.74 & 38.04 & 27.79 & 30.91 & 36.11 & 43.81 & 33.46 & 38.68 & 38.92 \\
\hline
\end{tabular}

processing best results $\left(\mathrm{T}_{\mathrm{C}}>80 \%\right)$ appeared for Kurtosis and LBC-II, whilst the PCT, Skewness, LBC-II and TSR processing provide $80 \%>\mathrm{T}_{\mathrm{C}}>70 \%$. However, other authors [45] demonstrated that not only the type of test procedure and/or the data processing algorithm used but also the power and rate of heating play a crucial role in ensuring detectable signals over hidden defects; for example, a suitable heating for CFRP laminates must be short and powerful [45].

\subsubsection{Signal to Noise Ratio}

The SNR analysis also could be applied to establish the more suitable processing methods in terms of accuracy of detectability $[29,46]$. Specifically, the SNR defines the contrast value in decibels $[\mathrm{dB}]$ between a defective zone and its neighbourhood area, evaluated as

$S N R=20 \cdot \log _{10} \cdot\left(\frac{\left|I_{\text {mean }}-D_{\text {mean }}\right|}{\sigma}\right)$

With $\boldsymbol{D}_{\text {mean }}$ and $\boldsymbol{I}_{\text {mean }}$ the average values of a defective and its neighbourhood un-damaged zones (Dim. $5 \times 5$ pixel) respectively and $\sigma$ the standard deviation of the noise.

For the reference plate, the corresponding SNR results of inspected defects are listed in Tables 4, evaluated in the relative processed maps. The data analysis shows the defect size influence on the SNR values that could vary from NAN or SNR $<0$ if defects result undetected or smaller to SNR $>0$ in case of bigger and better identified defects [29]. Only one negative SNR value is observed for the smaller defect in the DAC map, whilst TSR and first derivative results provides the higher values of the SNR parameter. The SNR clearly depends on the defect's diameter, where the smaller D7 defect computes the worse signal to noise ratio $(\mathrm{SNR}<0)$ and higher SNR are observed for greater defect D1. However, D7 defect shows minor SNR and this behaviour could be determined from the position on the specimen, strongly influenced by the edge effect. It is observed that the PCT based data significantly enhanced the SNR of defects with respect to the relative EOF data; the SNR differences between skewness/kurtosis and LBC-II results seem to be negligible as compared. The SNR also depends on applied processing technique and the $\mathrm{LBC}$ approaches seem to enhance the SNR of smaller defects, so the further accuracy of detectability is improved.

\section{Conclusions}

In this work, four carbon-epoxy composite elements including a complex multi-stringer panel with backside stiffeners and multiple damage features (internal delaminations and cut of skin-stiffener continuity) and widespread-porosity panels are inspected, employing pulsed thermography. Raw thermal sequences are evaluated as data input to detect the internal damages (polymeric inserts for reference plate and delamination for multi-stringer) and to select different regions of interest in defective and undamaged zones.

Subsequentially, the thermographic acquisitions are postprocessed using contrast methods (normalized contrast and DAC), methods based on standardization (skewness, kurtosis), TSR and derivatives, PCT and two proposed techniques (LBC-I and LBC-II) on a reference CRFP plate and on multi-stringer. Different results highlight the specific advantages of several processing methods, i.e. the PCT approach results a robust and well-established technique for defect detecting, but difficult to interpret than DAC and TSR. The resulting LBC-I technique provides enhanced results with respect to PCT approach and others in terms of Tanimoto criterion values and SNR technique, applied for some defects in the reference CFRP plate.

However, the correct defect identification would be almost difficult when the component shows a widespread damage and diffused flaws, as seen with two panels erroneously manufactured during curing phase. In these cases, the application of LBC-II and of statistical methods based on standardization significantly improved the detectability of damage features. These processing approaches provides a fast simplified post-processing analysis of a unique processed image containing all the relevant information, without definition of undamaged zone. In conclusion, a trade-off between processing time and defect enhancement is usually a very challenging issue in thermal image-processing. 
Acknowledgements The authors would like to thank Prof. Umberto Galietti, Eng. Davide Palumbo and Eng. Rosa de Finis for sharing thermographic equipment.

Funding Open access funding provided by Università del Salento within the CRUI-CARE Agreement.

\section{Declarations}

Conflict of interest The authors declare that they have no known competing financial interests or personal relationships that could have appeared to influence the work reported in this paper.

Open Access This article is licensed under a Creative Commons Attribution 4.0 International License, which permits use, sharing, adaptation, distribution and reproduction in any medium or format, as long as you give appropriate credit to the original author(s) and the source, provide a link to the Creative Commons licence, and indicate if changes were made. The images or other third party material in this article are included in the article's Creative Commons licence, unless indicated otherwise in a credit line to the material. If material is not included in the article's Creative Commons licence and your intended use is not permitted by statutory regulation or exceeds the permitted use, you will need to obtain permission directly from the copyright holder. To view a copy of this licence, visit http://creativecommons.org/licenses/by/4.0/.

\section{References}

1. Al-Lami, A., Hilmer, P., Sinapius, M.: Eco-efficiency assessment of manufacturing carbon fiber reinforced polymers (CFRP) in aerospace industry. Aero. Sci. Technol. (2018). https://doi.org/ 10.1016/j.ast.2018.06.020

2. Shehab, E., Ma, W., Wasim, A.: Manufacturing cost modelling for aerospace composite applications. In: Stjepandić, J., Rock, G., Bil, C. (eds.) Concurrent Engineering Approaches for Sustainable Product Development in a Multi-Disciplinary Environment. Springer, London (2013)

3. Timmis, A.J., Hodzic, A., Koh, L., et al.: Environmental impact assessment of aviation emission reduction through the implementation of composite materials. Int. J. Life Cycl. (2015). https://doi. org/10.1007/s11367-014-0824-0

4. Scelsi, L., Bonner, M., Hodzic, A., et al.: Potential emissions savings of lightweight composite aircraft components evaluated through life cycle assessment. Express Polym. Lett. (2011). https://doi.org/10.3144/expresspolymlett.2011.20

5. Wang, B., Zhong, S., Lee, T.L., Fancey, K.S., Mi, J.: Non-destructive testing and evaluation of composite materials/structures: a state-of-the-art review. Adv. Mech. Eng. (2020). https://doi.org/ $10.1177 / 1687814020913761$

6. Duchene, P., Chaki, S., Ayadi, A., et al.: A review of non-destructive techniques used for mechanical damage assessment in polymer composites. J. Mater. Sci. (2018). https://doi.org/10.1007/ s10853-018-2045-6

7. Hamdan, A., Sultan, M.T.H., Mustapha, F.: 11 - Structural Health Monitoring of Biocomposites, Fibre-Reinforced Composites and Hybrid Composites, A volume in Woodhead Publishing Series in Composites Science and Engineering Woodhead Publishing Series in Composites Science and Engineering. Woodhead Publishing, Sawston, pp. 227-242 (2019)

8. de Castro, B.A., Baptista, F.G., Ciampa, F.: A comparison of signal processing techniques for impedance-based damage characterization in carbon fibers under noisy inspections. Mater. Today Proc. (2020). https://doi.org/10.1016/j.matpr.2020.03.470

9. Cantwell, W.J., Morton, J.: The significance of damage and defects and their detection in composite materials: a review. J. Strain Anal. Eng. Des. 27, 9-42 (1992). https://doi.org/10.1243/03093 247V271029

10. Nsengiyumva, W., Zhong, S., Qiukun Zhang, J., Zhonga, J., Huang, Y.: Advances, limitations and prospects of nondestructive testing and evaluation of thick composites and sandwich structures: a state-of-the-art review. Compos. Struct. 256, 112951 (2020). https://doi.org/10.1016/j.compstruct.2020.112951

11. Usamentiaga, R., Venegas, P., Guerediaga, J., et al.: Infrared thermography for temperature measurement and non-destructive testing. Sensors (2014). https://doi.org/10.3390/s140712305

12. Zauner, G., Mayr, G., Hendorfer, G.: Comparative defect evaluation of aircraft components by active thermography, Proc. SPIE 7251. In: Proceedings of the Image Processing: Machine Vision Applications II, 72510J, doi: https://doi.org/10.1117/12.806795 (2009)

13. Vavilov, V.P., Burleigh, D.D.: Review of pulsed thermal NDT: physical principles, theory and data processing. NDT Int. 73, 28-52 (2015). https://doi.org/10.1016/j.ndteint.2015.03.003

14. Yoonjae, C., Shrestha, R., Seungju, L., Wontae, K.: thermographic inspection of internal defects in steel structures: analysis of signal processing techniques in pulsed thermography. Sensors 20(21), 6015 (2020). https://doi.org/10.3390/s20216015

15. Yuan, L., Zhu, X., Sun, Q., Liu, H., Yuen, P., Liu, Y.: Automatic extraction of material defect size by infrared image sequence. Appl. Sci. 10(22), 8248 (2020). https://doi.org/10.3390/app10 228248

16. Poelman, G., Hedayatrasa, S., Segers, J., Van Paepegem, W., Kersemans, M.: an experimental study on the defect detectability of time-and frequency-domain analyses for flash thermography. Appl. Sci. 10(22), 8051 (2020). https://doi.org/10.3390/app10 228051

17. Galietti, U., D’Accardi, E., Palumbo, D., Tamborrino, R.: A quantitative comparison among different algorithms for defects detection on aluminum with the pulsed thermography technique. Metals 8(10), 859 (2018). https://doi.org/10.3390/met8100859

18. Yanjie, W., Dgelom, S., Shuangshuang, M., Dongsheng, Z.: An infrared defect sizing method based on enhanced phase images. Sensors 20(13), 3626 (2020). https://doi.org/10.3390/s20133626

19. Ibarra-Castanedo, C., Maldague, X.: Handbook of technical diagnostics: fundamentals and application to structures and systems. In: H Czichos (eds.) Part II: Methods and Techniques for Diagnostics and Monitoring, Cap. 10: Infrared Thermography. Springer Science \& Business Media, Berlin (2013)

20. Maldague, X.: Theory and Practice of Infrared Technology for Nondestructive Testing, Wiley Series in Microwave and Optical Engineering. Wiley, Hoboken (2001)

21. Pilla, M., Klein, M., Maldague, X., Salerno, A.: New absolute contrast for pulsed thermography. In: Balageas, D., Busse, G., Carlomagno, G. (eds.) Proceedings of QIRT02, Dubronvik, Croatia, pp. 53-58. doi: https://doi.org/10.21611/qirt.2002.004 (2002)

22. Shepard, S.M., Lhota, J.R., Rubadeux, B.A., Wang, D., Ahmed, T.: Reconstruction and enhancement of active thermographic image sequences. Opt. Eng. (2003). https://doi.org/10.1117/1. 1566969

23. Ramirez-Granados, J.C., Paez, G., Strojnik, M.: Reconstruction and analysis of pulsed thermographic sequences for nondestructive testing of layered materials. Appl. Opt. (2010). https://doi. org/10.1364/AO.49.00149428

24. Rajic, N.: Principal component thermography, Defense Science and Technology Organization Victoria (Australia) Aeronautical and Maritime Research Laboratory, Technical report 
DSTO-TR-1298. https://apps.dtic.mil/dtic/tr/fulltext/u2/a4058 57.pdf (2002)

25. Maldague, X.: Nondestructive Evaluation of Materials by Infrared Thermography. Springer, London (1993)

26. Dattoma, V., Panella, F.W., Pirinu, A., Saponaro, A.: Advanced NDT methods and data processing on industrial CFRP components. Appl. Sci. 9(3), 1-17 (2019). https://doi.org/10.3390/app90 30393

27. Dattoma, V., Nobile, R., Panella, F.W., Saponaro, A.: NDT thermographic techniques on CFRP structural components for aeronautical application. Procedia Struct. Integr. 8, 452-461 (2018). https://doi.org/10.1016/j.prostr.2017.12.045

28. Vavilov, V.P., Bison, P.G., Grinzato, E.G.: Statistical evaluation of thermographic NDT performance applied to CFRP. Int. Soc. Opt. Photon. (1996). https://doi.org/10.1117/12.235396

29. Hidalgo-Gato, R., Andrés, J.R., López-Higuera, J.M., Madruga, F.J.: Quantification by signal to noise ratio of active infrared thermography data processing techniques. Opt. Photon. J. (2013). https://doi.org/10.4236/opj.2013.34A004

30. Panella, F.W., Pirinu, A., Dattoma, V.: A brief review and advances of thermographic image - processing methods for IRT inspection: a case of study on GFRP plate. Exp. Technol. (2020). https://doi.org/10.1007/s40799-020-00414-4

31. Gonzalez, D., Ibarra-Castanedo, C., Pilla, M. et al.: Automatic interpolated differentiated absolute contrast algorithm for the analysis of pulsed thermographic sequences. In: Proceedings of the in Quantitative Infrared Thermography. https://doi.org/10. 21611/qirt.2004.014 (2004)

32. Koshti, A.M.: A method to measure and estimate normalized contrast in infrared flash thermography. In: Proceedings of the Conference: SPIE Smart Structures and Materials + Nondestructive Evaluation and Health Monitoring. https://doi.org/10.1117/ $12.2211676(2016)$

33. Carslaw, H., Jaeger, J.: Conduction of Heat in Solids, 2nd edn. Claredon Press, Oxford (1986)

34. Ibarra-Castanedo, C., González, D.A., Galmiche, F., Bendada, A., Maldague, X.P.: On signal transforms applied to pulsed thermography. Recent Res. Dev. Appl. Phys. 9, 101-112 (2006)

35. Madruga, F.J,, Ibarra-Castanedo, C., Conde, O.M., LopezHiguera, J.M., Madalgue, X.: Automatic data processing based on the skewness statistic parameter for subsurface defect detection by active infrared thermography. In: Proceedings of the 9th international conference in quantitative infrared thermography (QIRT). http://citeseerx.ist.psu.edu/viewdoc/download?doi=10.1. 1.558.8877\&rep $=$ rep $1 \&$ type $=$ pdf $(2008)$

36. Madruga, F.J., Ibarra-Castanedo, C., Condea, O.M., et al.: Infrared thermography processing based on higher-order statistics. NDT \& E Int. 43(8), 661-666 (2010). https://doi.org/10.1016/j.ndteint. 2010.07.002
37. Balageas, D.L., Chapuis, B., Deban, G., Passilly, F.: Improvement of the detection of defects by pulse thermography thanks to the TSR approach in the case of a smart composite repair patch. Quant. InfraRed Thermogr. J. 7, 167-187 (2010). https://doi.org/ 10.3166/qirt.7.167-187

38. Shepard, S.M., Lhota, J.R., Rubadeux, B.A., Ahmed, T., Wang, D.: Enhancement and reconstruction of thermographic NDT data. In: Proceedings of SPIE, Thermosense XXIV, 4710: pp. 531-535, Aero-Sense 15 March 2002, Orlando, United States. https://doi. org/10.1117/12.459603 (2002)

39. Zheng, K., Chang, Y.S., Wang, K.H., Yao, Y.: Improved nondestructive testing of carbon fiber reinforced polymer (CFRP) composites using pulsed thermograph. Polym. Test. (2015). https://doi.org/10.1016/j.polymertesting.2015.06.016

40. Shepard, S.M., Hou, J., Lhota, J.R., Golden, J.M.: Automated processing of thermographic derivatives for quality assurance. Opt. Eng. 46(5), 1-14 (2007). https://doi.org/10.1117/1.2741274

41. Wang, Z., Tian, G., Meo, M., Ciampa, F.: Image processing based quantitative damage evaluation in composites with long pulse thermography. NDT \& E Int. 99, 93-104 (2018). https://doi.org/ 10.1016/j.ndteint.2018.07.004

42. Rajic, N.: Principal component thermography for flaw contrast enhancement and flaw depth characterization in composite structures. Compos. Struct. 58(4), 581 (2002). https://doi.org/10.1016/ S0263-8223(02)00161-7

43. Rajic, N.: A quantitative approach to active thermographic inspection for material loss evaluation in metallic structures. Res. Nondestruct. Eval. 12(2), 119-131 (2000). https://doi.org/10.1080/ 09349840009409654

44. Chrysafi, A.P., Athanasopoulos, N., Siakavellas, N.J.: Damage detection on composite materials with active thermography and digital image processing. Int. J. Therm. Sci. 116, 242-253 (2017)

45. Sojasi, S., Fariba Khodayar, F., Lopez, F., Ibarra-Castando, C. et al.: Infrared testing of CFRP components: comparisons of approaches using the tanimoto criterion. In: Proceedings of NDT in Canada 2015 Conference. https://www.ndt.net/events/NDTCa nada2015/app/content/Paper/27_Sojasi.pdf (2015)

46. Shrestha, R., Kim, W.: Non-destructive testing and evaluation of materials using active thermography and enhancement of signal to noise ratio through data fusion. Infrared Phys. Technol. (2018). https://doi.org/10.1016/j.infrared.2018.08.027

Publisher's Note Springer Nature remains neutral with regard to jurisdictional claims in published maps and institutional affiliations. 